\title{
Microbialitos da Sequência Balbuena IV (Daniano), Bacia de Salta, Argentina: caracterização de intrabioarquiteturas e de microciclos
}

\author{
Rodrigo Brandão BUNEVICH ${ }^{1}$, Leonardo BORGHI${ }^{2}$, Guilherme Pederneiras Raja GABAGLIA ${ }^{1}$, \\ Gerson José Salamoni TERRA ${ }^{1}$, Ednilson BENTO FREIRE ${ }^{1}$, Ricardo LYKAWKA ${ }^{1}$ \& Daniel Galvão \\ Carnier FRAGOSO ${ }^{1}$
}

1 Universidade Petrobras, Petrobras S.A. Rua Ulisses Guimarães, 565, CEP 20.211-225, Rio de Janeiro, RJ, Brasil (rodrigo. bunevich@petrobras.com.br, guilhermeraja@petrobras.com.br, gersonjsterra@gmail.com, ebfreire@petrobras.com.br, rlykawka@petrobras.com.br, danielfragoso@petrobras.com.br).

2 Lagesed - Laboratório de Geologia Sedimentar, Instituto de Geociências, Universidade Federal do Rio de Janeiro. Av. Athos da Silveira Ramos, 274, s/J1-011. CEP 21.941-916, Rio de Janeiro, RJ, Brasil (lborghi@geologia. ufrj.br).

Recebido em 02/2016. Aceito para publicação em 07/2017.

Versão online publicada em 21/10/2017 (www.pesquisasemgeociencias.ufrgs.br)

Resumo - Microbialitos gerados em ambiente deposicional lacustre apresentam grande diversidade de estruturas e texturas internas. A organização e a caracterização do arranjo formado por esses atributos correspondem ao que se denomina intrabioarquitetura. Este trabalho tem o objetivo de identificar os principais tipos de intrabioarquiteturas nos microbialitos da Sequência Balbuena IV (Daniano, Bacia de Salta, Argentina) em escala mesoscópica $\left(10^{0}-10^{-2} \mathrm{~m}\right)$ e a interpretação cíclica da recorrência dos componentes que formam estas intrabioarquiteturas, em escala microscópica. Foram reconhecidos sete padrões intrabioarquiteturais, assim denominados: Microbialito Aglutinante de grão grosso (MA-gg); Microbialito Bandeado Fasciculado/Aglutinante de grão fino (MBFA-gf); Microbialito Pseudo-microcolunar Aglutinante de micrita (MPMA-m); Microbialito Arbustiforme Microgrumoso Aglutinante de grão fino (MArbMA-gf); Microbialito Dendriforme Microgrumoso Aglutinante de grão fino (MDMA-gf); Microbialito Bandeado Fasciculado/Aglutinante de grão fino com esferulito (MBFA-gf,esf) e Estromatólito Microgrumoso/Aglutinante de grão grosso (EMA-gg). Essas intrabioarquiteturas foram agrupadas e relacionadas a três tipos de microciclos deposicionais. Os microciclos possibilitam organizar o registro microbial em escala meso- e microscópica. Essa organização cíclica está relacionada às variações climáticas, que afetam o nível de base, o aporte sedimentar e os processos biológicos e geoquímicos do sistema lacustre. Portanto, foi possível associar a formação dos microbialitos a períodos de maior ou de menor aridez no ambiente deposicional.

Palavras-chave: Sedimentação lacustre, Paleoclima, Formação Yacoraite, Sub-bacia de Metán-Alemania.

\begin{abstract}
Microbialites of Balbuena IV Sequence (Danian), Salta Basin, Argentina: intraBIOARCHITECTURAL CHARACTERIZATION AND DEFINITION OF MICROCYCLES. Microbialites produced in lacustrine environment exhibit a wide range of internal structures and textures. The organization and the characterization of the arrangement formed by these attributes are denominated as intrabioarchitectures. This work sought to identify the main types of intrabioarchitectural patterns in the microbialites of Balbuena IV Sequence (Danian, Salta Basin, Argentina) in mesoscopic scale $\left(10^{0}-10^{-2} \mathrm{~m}\right)$ and the cyclical interpretation for the recurrence of the components that build these intrabioarchitectures, in microscopic scale. Seven main intrabioarchitectural types were recognized, and denominated as: coarse grain agglutinated microbialite (MA-gg); fine grain agglutinated and sparite fan crust, banded microbialite (MBFA-gf); micrite agglutinated, pseudo-microcolumnar microbialite (MPMA-m); fine grain agglutinated, grumous, shrubby microbialite (MArbMA-gf); fine grain agglutinated grumous, dendriform microbialite (MDMA-gf); fine grain agglutinated with esferulites, sparite fan crust, banded microbialite (MBFA-gf,esf); coarse grain agglutinated, grumous, stromatolite (EMA-gg). These intrabioarchitectures were grouped and related to three types of microcycles. The microcycles allow organizing the microbial record in a meso- and microscopic scale. That cyclic organization is related to climatic variations that affect the base level, the input of siliciclastics sediments, the biotic and geochemical processes in lake system. Therefore, it was possible to associate the formation of microbialites to phases of higher or lower aridity in the depositional environment.
\end{abstract}

Keywords: Lacustrine sedimentation, Paleoclimate, Yacoraite Formation, Sub-basin Metán-Alemania 


\section{Introdução}

Os microbialitos constituem depósitos organo-sedimentares (Burne \& Moore, 1987), cuja gênese está relacionada, principalmente, às atividades metabólicas de micro-organismos (bactérias, algas, arqueobactérias, etc.) e às suas relações com o meio físico. Nesses depósitos, são observadas distintas morfologias, estruturas, texturas e composições que auxiliam na caracterização paleoambiental, evidenciando as variações do nível de base, a velocidade de sedimentação e a variedade de partículas disponíveis no ambiente sedimentar.

0 estudo de microbialitos lacustres passou a receber maior destaque após as descobertas dos reservatórios gigantes offshore do pré-sal (de idade cretácica) no Brasil. A Bacia de Salta é considerada um dos melhores análogos para a compreensão da organização estratigráfica e do processo sedimentar em depósitos lacustres, podendo auxiliar no entendimento dos reservatórios do pré-sal (Terra et al., 2012).

Localizada na região noroeste da Argentina, a Sub-bacia Metán-Alemania, que se insere no contexto da Bacia de Salta, registra uma grande diversidade de microbialitos de origem lacustre. Esses depósitos são denominados Supersequência Balbuena, unidade integrante do Grupo Salta, cujo registro sedimentar compreende desde o final do período Cretáceo até o início do Paleógeno (Hernández et al., 1999). Essa supersequência é subdividida da base para o topo em quatro Sequências: Balbuena I, II, III e IV (Boll, 1991; Hernández et al., 1999). Para essas quatro Sequências, o arcabouço estratigráfico e a correlação em alta resolução em escala de bacia foram estabelecidos por Bento Freire (2012), Pedrinha Guimarães (2014) e Roemers de Oliveira (2014), os quais atribuem o controle do nível de base às variações climáticas decorrente dos ciclos de Milankovitch.

Este trabalho apresenta o resultado da caracterização intrabioarquitetural dos microbialitos da Sequência Balbuena IV, bem como o controle cíclico dos arranjos em altíssima frequência na escala dos ciclos suborbitais (millennial scale cycles).

\section{2 Área, materiais e métodos}

\subsection{Aspectos geológicos e localização da área de es- tudo}

A Bacia de Salta corresponde a uma importante feição paleogeomórfica, de aproximadamente $150.000 \mathrm{~km}^{2}$, que se estende desde o noroeste da Argentina até a parte sul da Bolívia e oeste do Paraguai (Del Papa \& Salftity,1999). A compartimentação estrutural da bacia permite dividi-la em quatro sub-bacias: Três Cruces, Lomas de Olmedo, Sey e Metán-Alemania, sendo esta última, a área alvo do presente estudo (Fig. 1).

A origem da Bacia de Salta está associada a um típico processo de rifteamento intraplaca durante o Cretáceo (Bianucci \& Homovoc, 1982). Esse processo está diretamente relacionado à ruptura do Gondwana e à abertura do Oceano Atlântico Sul.

A fase pré-rifte da bacia é formada por rochas do embasamento de idade meso-neoproterozoico/ Paleozoico (Bianucci \& Homovoc, 1982; Salfity \& Marquillas, 1989). Esse embasamento é composto pelas unidades metassedimentares e sequências vulcanoclásticos-magmáticas intrusivas relacionadas à evolução da placa sul-americana na região noroeste argentina. A fase rifte é caracterizada como produto da distensão crustal ao longo do Cretáceo, originando depocentros com mais de $4.000 \mathrm{~m}$ de profundidade (Marquillas et al., 2005). As rochas sedimentares da Supersequência Pirgua, que preencheram esses depocentros têm seu limite inferior marcado por uma discordância angular com o embasamento (Hernández et al., 1999).

A Supersequência Balbuena foi depositada em contexto de bacia tipo sag entre 75 e $63 \mathrm{Ma}$. Hernández et al. (1999) dividem essa Supersequência em quatro Sequências de terceira ordem (Fig. 2).

A Sequência Balbuena I é composta predominantemente por fácies siliciclásticas, depositadas por sistema eólico. Sua deposição foi responsável pela peneplanização do topo da topografia herdada da fase rifte, sob a qual se implantou um sistema lacustre com alternância de sedimento carbonático e pelítico siliciclástico.

A Sequência Balbuena II apresenta maior extensão espacial em comparação com a anterior. Pode ser dividida em duas seções: a basal, constituída de depósitos calcários intercalados com clásticos trativos e pelitos, os quais foram depositados em ambiente lacustre; e a superior, na qual predominam rochas clásticas formadas a partir de depósitos fluviais progradantes.

A Sequência Balbuena III, em comparação com as demais, é a que apresenta menor espessura e extensão. Na porção central da bacia predominam pelitos intercalados com arenitos muito finos e nas zonas de borda conglomerados fluviais.

A Sequência Balbuena IV, cuja abrangência em área é superior às demais, apresenta geometria tabular a suavemente cuneiforme. Seu registro deposicional é marcado por microbialitos, margas, 


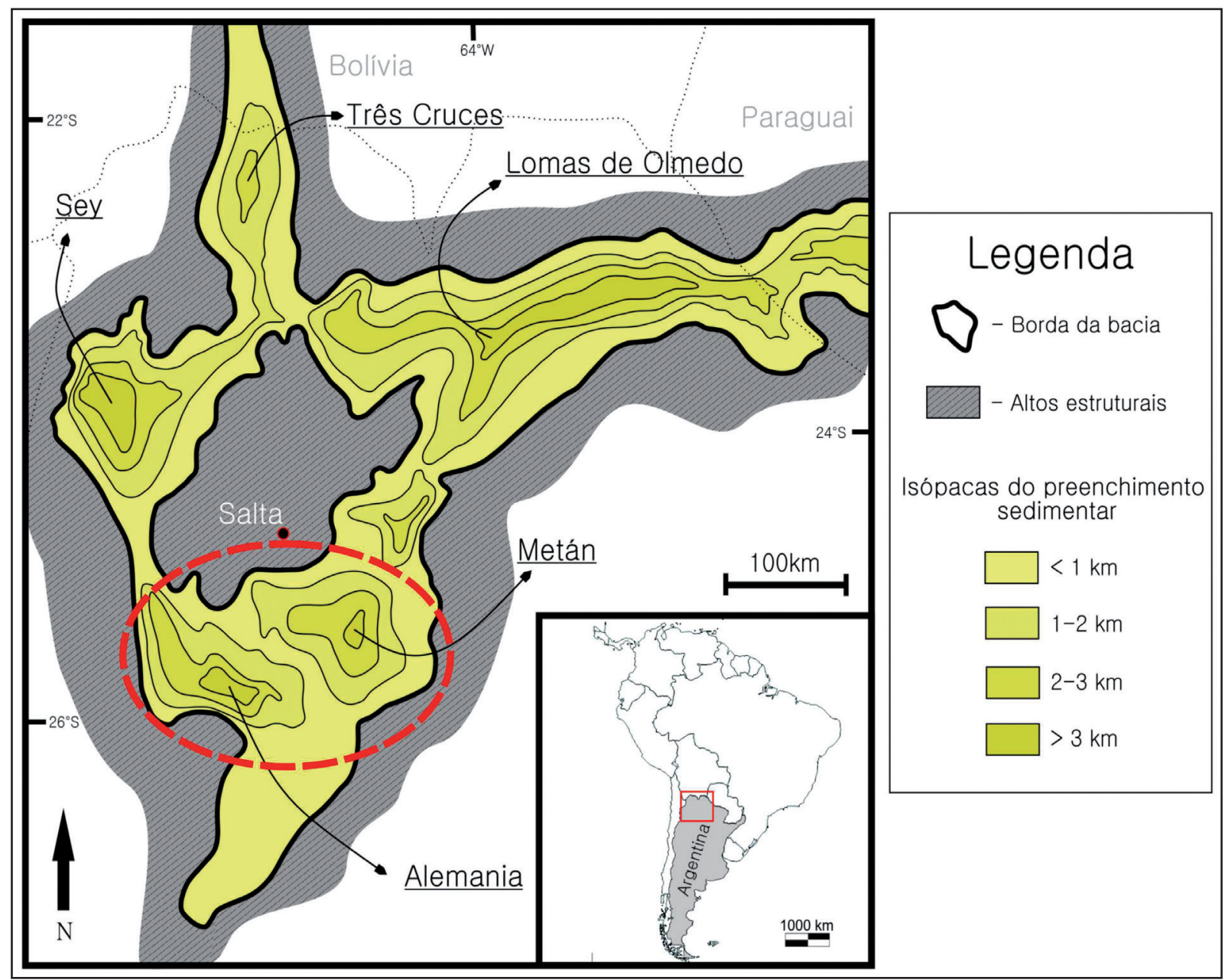

Figura 1. Mapa de localização da Bacia de Salta com destaque para a área de estudo (Salfity \& Marquillas, 1994; Sabino, 2004). Figure 1. Location map of the Salta Basin showing the study area (Salfity \& Marquillas,1994; Sabino, 2004).

siltitos, argilitos e, subordinadamente, arenitos quartzosos arcoseanos e carbonáticos na porção central da bacia. Nas regiões marginais, em especial na borda oeste (região de Cachi), a sequência é composta principalmente de arenitos quartzo-feldspáticos, arcóseos e arenitos conglomeráticos.

A área de estudo localiza-se na Província de Salta, noroeste da Argentina, na região do Dique Cabra Corral e adjacências (Fig. 3).

Nessa região observa-se o empilhamento completo da Supersequência Balbuena, a qual exibe uma grande diversidade de microbialitos de origem lacustre com distintas morfologias que foram interpretadas por Bento Freire (2012) como produto das variações do nível de base controlado pelo clima. De acordo com esse autor, as morfologias mais achatadas (tabular e planar) teriam sido formadas em períodos mais áridos, com menor acomodação; já as morfologias dômicas estariam relacionadas a períodos mais úmidos e com maior acomodação (Fig. 4).

\subsection{Materiais e Métodos}

0 afloramento estudado neste trabalho corresponde à seção tipo da Sequência Balbuena IV, localizado nas coordenadas 20J 0262208/7202000 - Datum: WGS 84 (Fig. 5).

0 fluxo de trabalho envolvendo microbialitos em suas diversas escalas de análise é apresentado na figura 6. As denominações utilizadas nesta representação esquemática, no que diz respeito à organização do depósito microbial, foram baseadas em Corbett et al. (2015). Esses autores adaptaram a nomenclatura das bioconstruções de corais para os depósitos microbiais (bioarquitetura, intrabioarquitetura e interbioarquitetura).

Este trabalho concentrou a coleta de dados e interpretações em meso- e microescala. Durante as atividades de campo foi realizada a análise em mesoescala das estruturas e texturas da parte interna dos microbialitos. Para uma caracterização preliminar dos diferentes tipos de intrabioarquite 


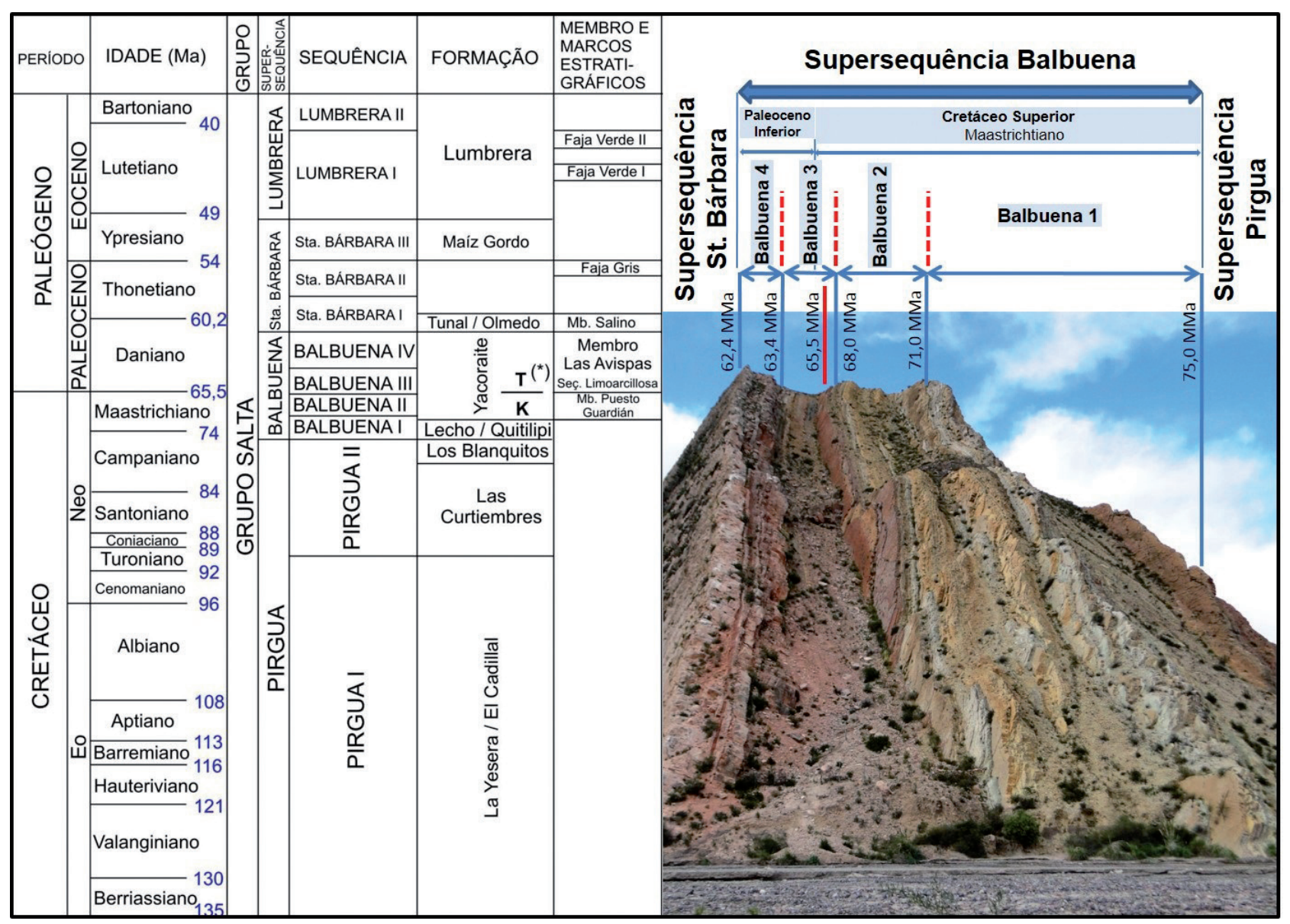

Figura 2. Diagrama estratigráfico do Grupo Salta. A imagem à direita representa o afloramento de Jueya, localizado a sul da Sub-bacia de Três Cruces, na qual é possível reconhecer todo o empilhamento estratigráfico da Supersequência Balbuena (Bento Freire, 2012). 0 intervalo corresponde na litoestratigrafia da bacia às formações Lecho e Yacoraite; as idades foram estabelecidas com base nos trabalhos de Hernández et al. (1999) e Marquillas et al. (2007).

Figure 2. Stratigraphic chart of the Salta Group. The image at the right side shows the Jueya outcrop, located at the south of Três Cruces sub-basin, where is possible to recognize all the Balbuena Supersequence's stratigraphic stacking (Bento Freire, 2012). The interval corresponds to Lecho and Yacoraite formation in the basin's lithoestratigraphy; the ages were based on the studies of Hernández et al. (1999) and Marquillas et al. (2007).

turas foram feitas amostragens na forma de plugs e fatias de rocha, as quais foram utilizadas para a confecção das lâminas petrográficas. Foram produzidas 80 lâminas para a análise microscópica e, para cada lâmina, feitos mosaicos de microfotografias. Para tal, utilizou-se microscópio petrográfico e lente objetiva de $5 \mathrm{x}$. Os mosaicos foram fundamentais para obter uma visão geral das variações de microestruturas e microtexturas que formam o arcabouço dos microbialitos, bem como caracterizar de forma mais precisa as intrabioarquiteturas e auxiliar na interpretação dos microciclos.

\section{Resultados}

Apresentam-se, inicialmente, os resultados da caracterização intrabioarquitetural, nas escalas meso- e microscópica, expostas na próxima seção. As denominações utilizadas para as intrabioarqui- teturas são compostas do termo microbialito, seguido da estrutura interna predominante, da textura que compõe o arcabouço (calcita fasciculada, microgrumosa ou aglutinante) e, por fim, do tamanho do grão, nos casos em que ocorre a textura do tipo aglutinante. Foram definidos sete tipos de intrabioarquiteturas nos microbialitos da Sequência Balbuena IV.

\subsection{Microbialito Aglutinante de grão grosso (MA-gg)}

Os microbialitos formam depósitos tabulares maciços, com topo ondulado pela ação de ondas. Os oncólitos predominam como principal tipo de grão em meio ao arcabouço microbial constituído por incipientes estruturas laminadas, podendo formar microcolunas de textura micrítica e micropeloidal (também denominada de microgrumosa). Os oncólitos exibem múltiplas fases de desenvol- 


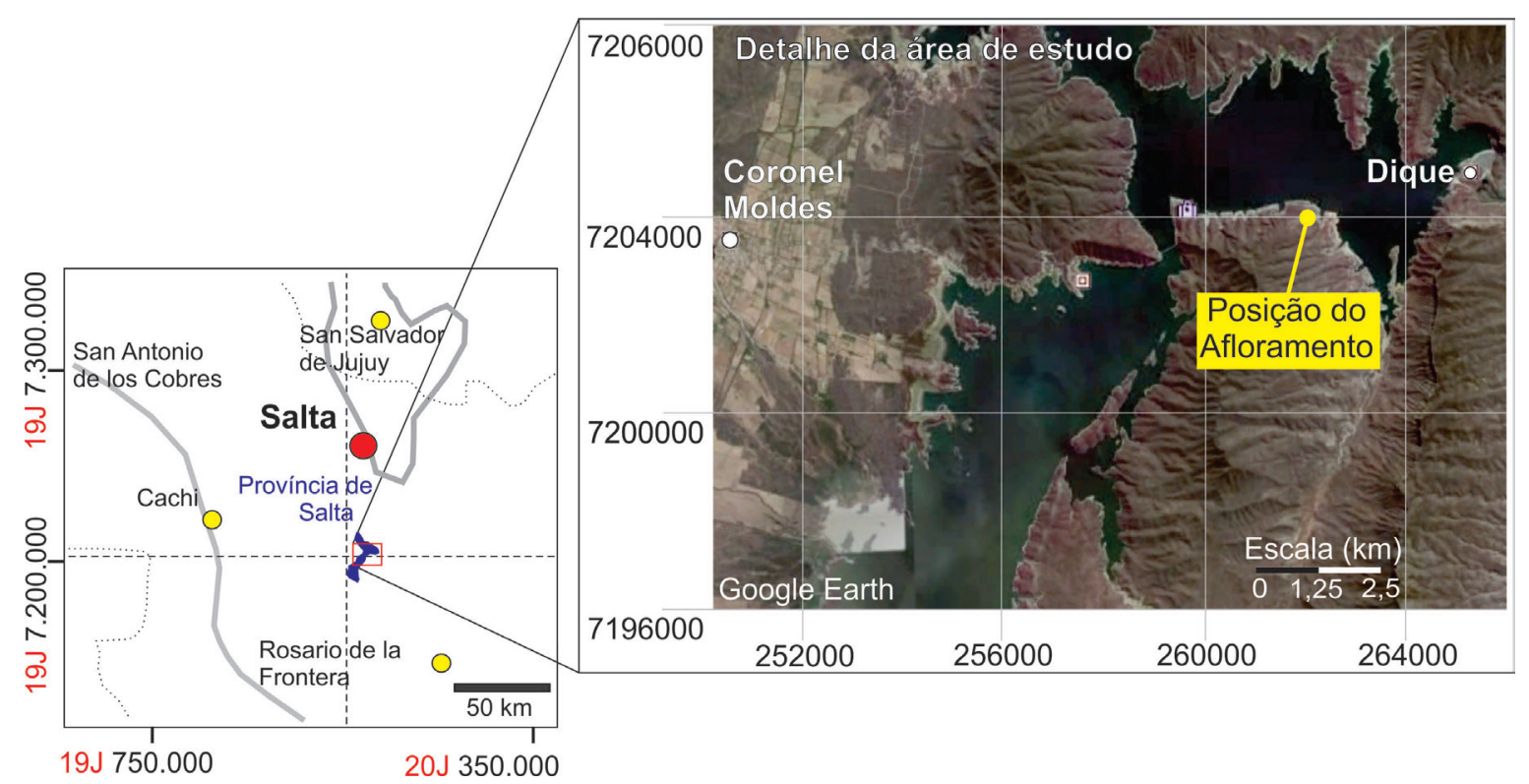

Figura 3. Mapa de localização da área de estudo. A) Posição aproximada dos limites da Bacia de Salta; B) Área de detalhamento e posição do afloramento tipo.

Figure 3. Location map of study area. A) Approximate position of Salta Basin boundaries; B) Area of detail work and position of the outcrop type.
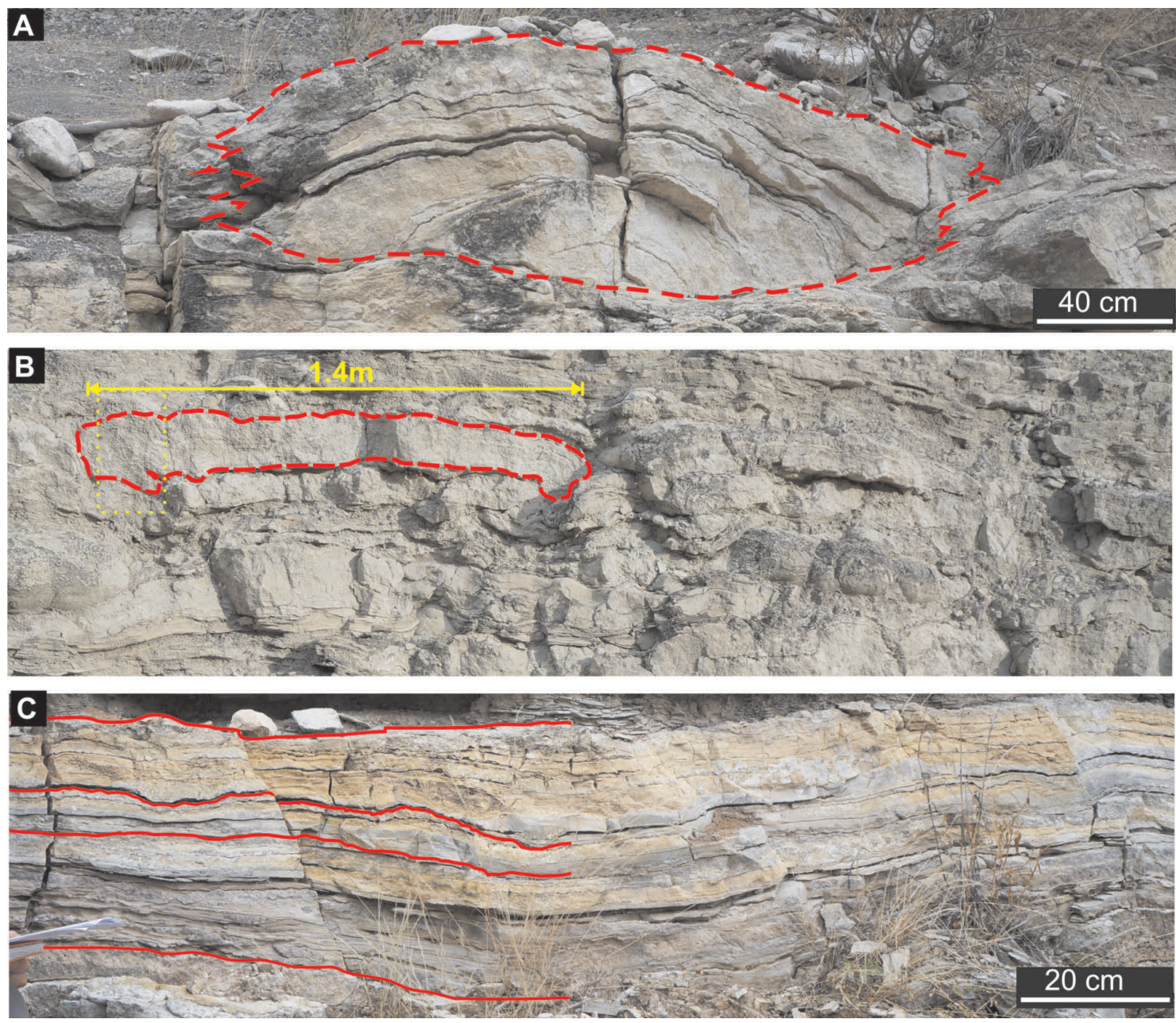

Figura 4. Principais tipos de morfologia externa dos microbialitos que ocorrem na Sequência Balbuena IV: A) Morfologia tipo dômica; B) Morfologia tabular; C) Morfologia planar.

Figure 4. Main types of external morphology of Sequency Balbuena IV microbialites: A) Domical morphology; B) Tabular morphology; C) Planar morphology. 


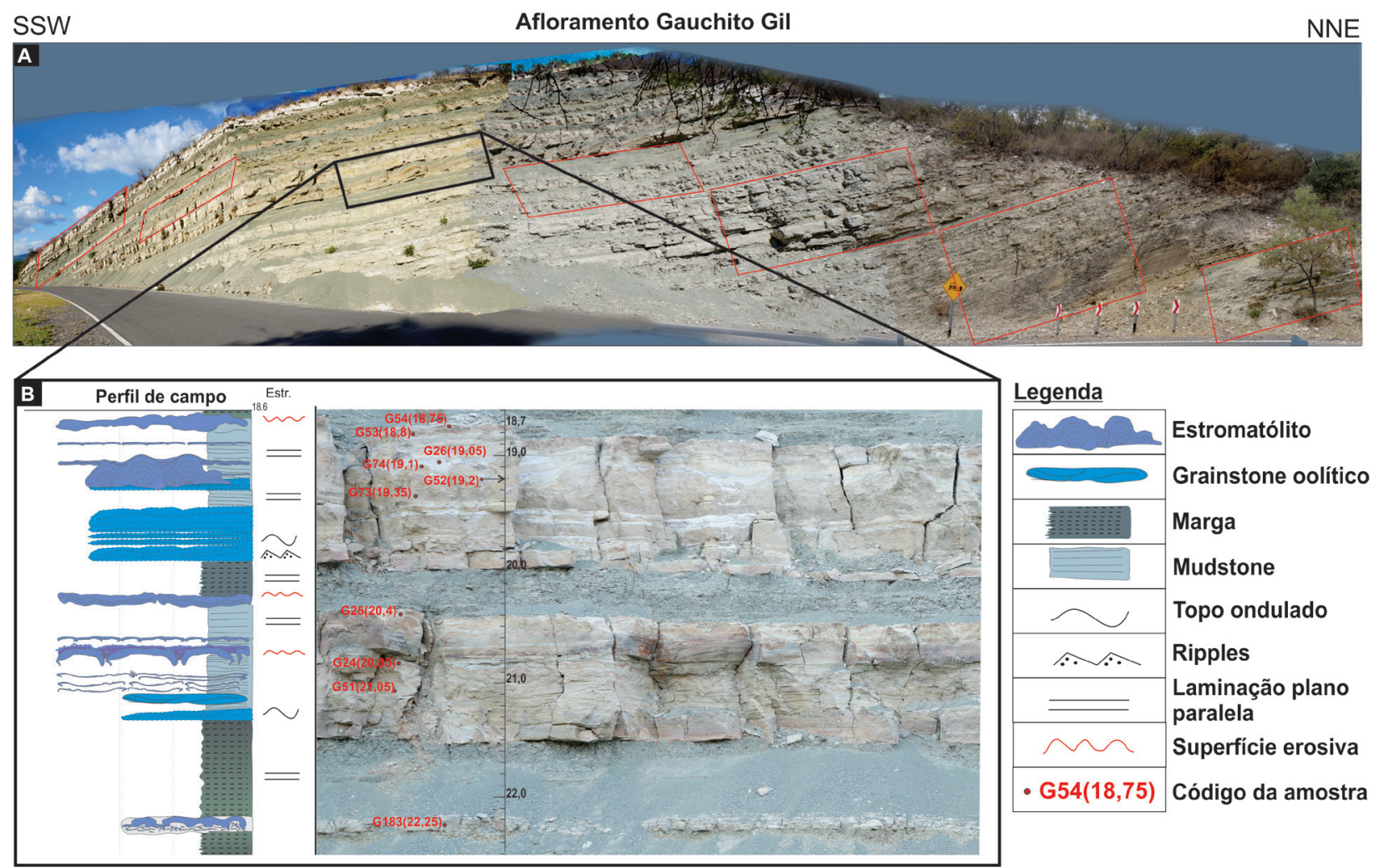

Figura 5. Afloramento tipo da Sequência Balbuena IV. A) Visão geral; B) Exemplo de perfil faciológico e imagem fotográfica de detalhe indicando a posição das amostras no afloramento.

Figure 5. Outcrop type of Balbuena IV Sequence. A) General overview; B) Example of faciologic log and photographic image showing the position of samples in the outcrop.
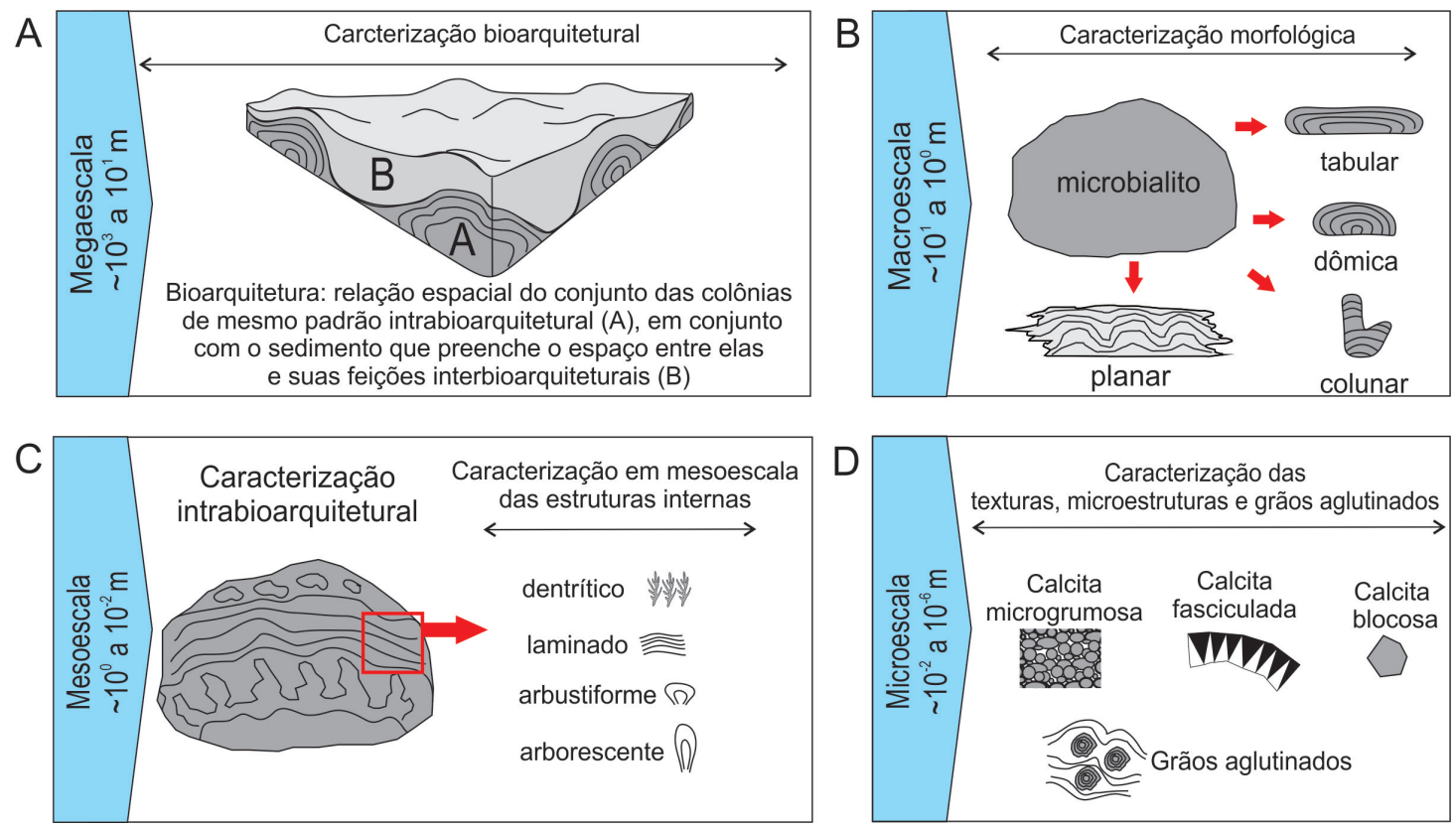

Figura 6. Denominações e escalas de trabalho em microbialitos: A) Megaescala: definição do arranjo bioarquitetural (morfologia do agrupamento das colônias de microbialitos em mounds, biostromas, formas isoladas, etc), e o tipo de relação de contato dos microbialitos com o sedimento associado; B) Macroescala: caracterização da morfologia individual da colônia de microbialito; C) Mesoescala: definição dos tipos de estruturas internas, denominadas como intrabioarquiteturas (Corbett et al., 2015); D) Microescala: descrição das texturas dos carbonatos, dos tipos de grãos aglutinados, das feições de exposição, mineralogia, etc.

Figure 6. Denominations and work scale in microbialites: A) Megascale: definition of the bioarchitectural arrangement (morphology of microbialite colonies grouping as mounds, biostroma, isolated forms, etc), as well as, the contact types and relationships of microbialites with the associated sediments; B) Macroscale: description of individual microbialite cologne morphology; C) Mesoscale: definition of microbial framework types, denominated as intrabioarchitecture (Corbett et al., 2015); D) Microscale: description of carbonate textures, agglutinated grains, exposure features, mineralogy, etc. 
vimento com dimensões de 0,2 a $2 \mathrm{~cm}$. Os intraclastos apresentam dimensão de 1 a $3 \mathrm{~cm}$, normalmente imersos em matriz micrítica com silte siliciclástico. Essa fácies normalmente ocorre na base dos intervalos carbonáticos (Figs. 7A e B).

Apesar do tamanho dos grãos observados nessa fácies, a formação de oncólitos e oólitos em sistemas lacustres não necessita de condições ambientais de alta energia, diferentemente dos marinhos. Como exemplo atual, o Lago de Genebra, que corresponde a parte sul do Lago Lemano (situado entre a França e a Suíça), cujos sedimentos de praia são compostos principalmente por oólitos, os quais sofrem retrabalhamento apenas cinco ou dez vezes ao ano. Atribui-se, portanto, a micro-or- ganismos o processo de precipitação do carbonato de cálcio na formação dos oólitos, os quais condicionam a forma dos grãos (Girardclos, 1993).

Interpreta-se condição semelhante de formação dos oncólitos e oólitos na intrabioarquitetura MA-gg. Os oncólitos, em parte, podem ter sido produzidos nas zonas mais rasas, sendo transportados durante a queda do nível de base para zonas que antes eram mais profundas. Nessa nova posição, as partículas continuam o processo de aglutinação de grãos em condição de energia decrescente, possibilitando a formação de oncólitos cada vez maiores, podendo atingir a granulometria seixo. Quando a energia do meio não é mais suficiente para movimentar esses grãos, ocorre a fixação e
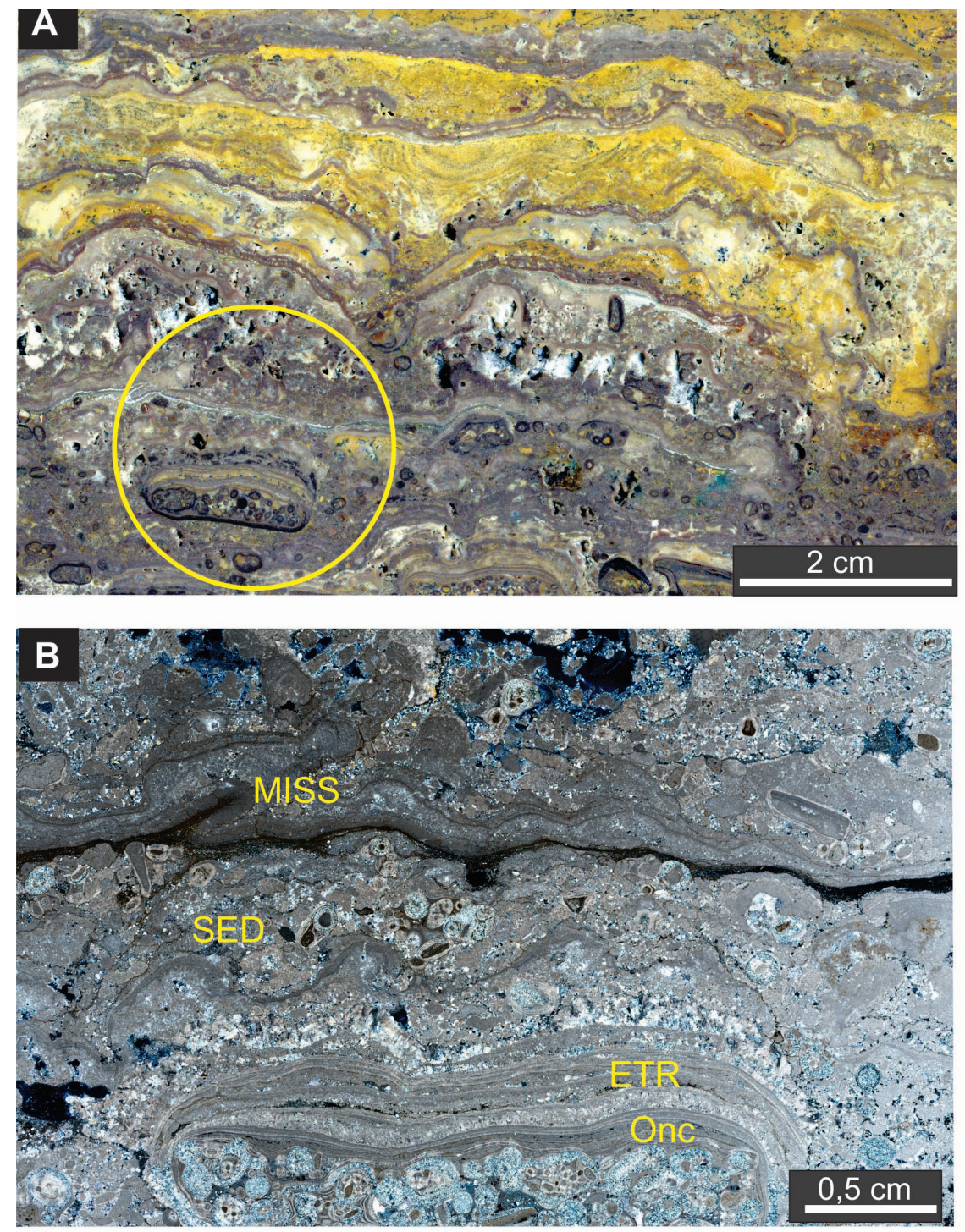

Figura 7. Microbialito Aglutinante de grão grosso (MA-gg). A) Aspecto geral macroscópico; B) Imagem petrográfica (com polarizador cruzado). MISS (Microbial Induced Sedimentary Structure): corresponde a estruturas laminadas incipientes formadas de calcita microgrumosa; SED: partículas retrabalhadas de oólitos, oncólitos e intraclastos; e Onc: oncólitos estabilizados pela ação microbial mostrando o início da formação de um estromatólito (ETR).

Figure 7. Coarse grain agglutinated microbialite (MA-gg). A) General macroscopic view; B) Petrographic image (using cross polarized light). MISS (Microbial Induced Sedimentary Structure): represents incipient layered structure composed of microgrumous calcite; SED: reworked particles oolites, oncolites and intraclasts; Onc: oncolites stabilized by microbial action, showing the start of stromatolite formation (ETR). 
o recobrimento do substrato oncolítico pelo EPS microbial, dando origem às estruturas laminadas microgrumosas levemente crenuladas, que nessa fase passam também a aglutinar micrita e silte.

\subsection{Microbialito Bandado Fasciculado/Aglutinante de grão fino (MBFA-gf)}

A intrabioarquitetura é formada pela sucessiva intercalação de bandas com espessura milimétrica, conforme ilustrado na figura 8A. Essas bandas são constituídas por: (i) microcolunas de textura aglutinante e (ii) por intervalos laminados formados de crosta de calcita com textura fasciculada.

Nos intervalos em que ocorrem as estruturas microcolunares, observa-se porosidade growthframework e intrapartícula. Os grãos aglutinados são principalmente oólitos e pelóides com menos de $0,5 \mathrm{~mm}$ de diâmetro sem matriz. Além desses dois tipos principais de porosidade, observa-se, também, a formação de porosidade devido à retração de argilominerais de esmectita. Nos intervalos mais maciços ocorre o predomínio de crostas de calcita fasciculada, com espessuras de até $2 \mathrm{~mm}$ e cristais bem formados. Na superfície, apresenta irregularidades, porém ausência de feições de dissolução por água meteórica.

$\mathrm{Na}$ literatura, são conhecidos microbialitos híbridos formados pela alternância de crostas fasciculadas e níveis micríticos. Constituem estromatólitos bem desenvolvidos, sem apresentar laminação isópaca (Riding, 2011). No registro geológico, trata-se de uma ocorrência comum nos microbialitos do Paleoproterozoico e Mesoproterozoico (Sami \& James, 1996), enquanto nos sedimentos atuais é comum a ocorrência em tufas lacustres (como as da Ilha de Andros).

Neste trabalho, interpreta-se que essa intrabioarquitetura é produto, principalmente, das variações geoquímicas do corpo lacustre. $\mathrm{Na}$ fase de desenvolvimento das crostas, há uma maior concentração (no corpo aquoso) de íons de sais de carbonato de cálcio, que possivelmente catalisados pela ação microbial, induziram a formação desses precipitados químicos. Durante as fases de menor estresse, as texturas microgrumosas, aglutinantes, bem como a precipitação de esmectitas voltaram a atuar.

\subsection{Microbialito Pseudo-microcolunar Aglutinante de micrita (MPMA-m)}

Esses microbialitos exibem formas que parecem microcolunas, porém são constituídas por lâminas contínuas, as quais apresentam moderado relevo sinóptico (até $1 \mathrm{~cm}$ de altura) e textura aglutinante de micrita (Fig. 9).

Nos depósitos atuais, essas estruturas são denominadas corrugadas ou wrinked, ocorrendo em sedimentos comumente dominados por cianobactérias, em meio a material siliciclástico, evaporítico e carbonático (Logan et al., 1974; Cameron et al., 1985; Gerdes et al., 2000). Com frequência, esses sedimentos sofrem submersão e emersão, quando ainda não estão litificados, ocorrendo assim a corrugação por perda de água.

Apesar de o depósito estudado apresentar, frequentemente, fragmentação das estruturas microbiais associadas a eventos de exposição, em particular, as lâminas com estruturas pseudo-microcolunares (ou laminação corrugada), não apresentam evidências diretas desse processo. Outra possibilidade de interpretação para o processo de corrugação, é que ele ocorra devido a uma característica do hábito de crescimento de determinada associação microbial.

\section{4 Microbialito Arbustiforme Microgrumoso Aglu- tinante de grão fino (MArbMA-gf)}

Apresenta formas arbustiformes que podem ramificar-se ou não, cuja razão largura/altura é aproximadamente 1. Em macroescala, apresentam um aspecto cloted, exibindo por vezes laminação interna discreta. No topo das estruturas arbustiformes, ocorrem intraclastos e, em meio a essas estruturas, sedimentos finos de composição mista (mudstone e silte siliciclástico), conforme apresentado na figura 10 . Na literatura, alguns trombólitos apresentam feições arborescentes ou com aspecto coagulado como, por exemplo, as Favosamaceria (Shapiro \& Awramik, 2006).

\section{5 Microbialito Dendriforme Microgrumoso Aglu- tinante de grão fino (MDMA-gf)}

Apresenta estruturas ramificadas com razão altura/largura maior do que 1 , podendo ligar-se por pontes. Essas estruturas são constituídas principalmente por calcita com textura microgrumosa e os espaços entre as estruturas microbiais encontram-se preenchidos por oólitos com diâmetro menor do que $0,5 \mathrm{~mm}$, intraclastos e silte siliciclásticos (Fig. 11).

Braga et al. (1995) atribuem a formação de estruturas dendriformes ou mais complexas a um processo irregular de aglutinação e calcificação microbial, incrustação esqueletal e processos erosivos. 

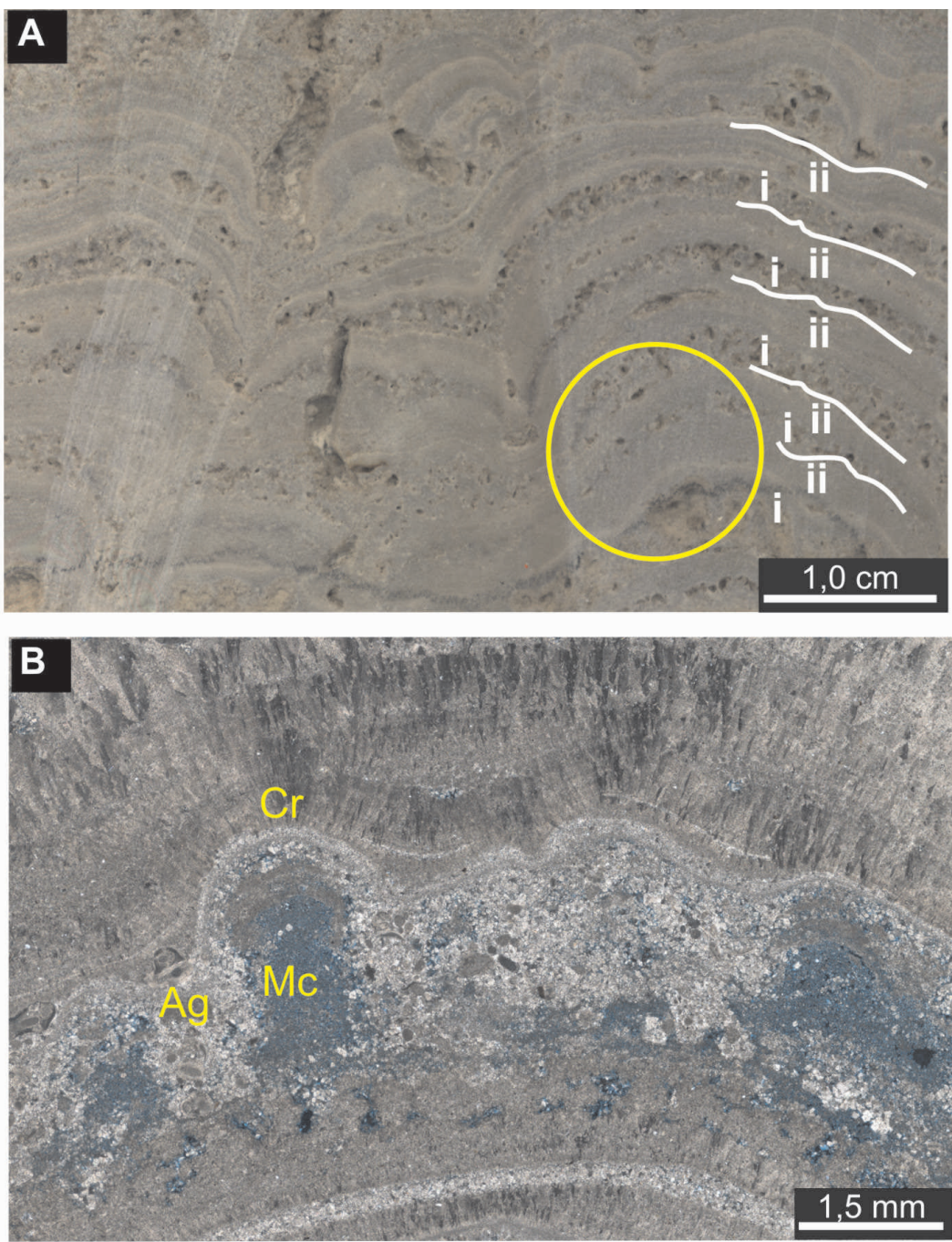

Figura 8. Microbialito Bandado Fasciculado/Aglutinante de grão fino (MBFA-gf). A) Aspecto geral macroscópico e representação do bandeamento composicional, dado pela alternância de "i" microcolunas de textura aglutinante e "ii" intervalos laminados de crosta de calcita com textura facicular; B) Imagem petrográfica (com polarizador paralelo). Mc: estruturas microcolunares formadas de calcita microgrumosa; Ag: grãos aglutinados (oólitos, pelóides e intraclastos); Cr: crosta de calcita fasciculada. Figure 8. Fine grain agglutinated and sparite fan crust, banded microbialite (MBFA-gf). A) General macroscopic view and representation of compositional band, given by alternation of " $i$ " microcolumns of agglutinated texture and "ii" laminated intervals of sparite; B) Petrographic image (using plane polarized light). Mc: microcolumnar structures with microgrumous calcite; Ag: binded grains (ooliths, peloids and intraclasts); Cr: sparite fan calcite crust.

Essas estruturas são interpretadas neste trabalho como sendo uma característica do hábito de crescimento de determinada associação microbial, a qual ocorre em ambiente de baixa energia, uma vez que se trata de uma estrutura mais delicada. Além disso, o preenchimento em meio às microcolunas dendríticas é constituído por sedimentos finos, principalmente mudstone e silte siliciclástico, o que corrobora para a interpretação de baixa energia do meio.

\subsection{Microbialito Bandado Fasciculado/Aglutinante de grão fino com esferulito (MBFA-gf,esf)}

Apresenta basicamente os mesmos elementos da intrabioarquitetura MBFA-gf. Porém, sua principal característica é a ocorrência de esferuli- tos e de cristal shrubs (Fig. 12).

De acordo com muitos autores, a origem dos esferulitos está vinculada a micro-organismos, especialmente bactérias (Danielli \& Edington, 1983; Deelman, 1975; Vogt, 1987; Del Moral et al., 1987; Chafetz \& Buczynski, 1992). Outros os associam a processos abióticos (Deelman, 1978; Lippman, 1973; Pentecost, 1990). Experimentos conduzidos em laboratório, sob condições estéreis, visando à precipitação de esferulitos e crostas, a partir de soluções super-saturadas (de composição química semelhante à verificada em lagos salinos alcalinos tal como Mono Lake), produziram cristais euhédricos a subédricos rômbicos de calcita. Incorporando-se argilas magnesianas (estevensita) à solução original ocorreu a precipitação de cristais de calcita na forma de placas. Os esferulitos somente fo- 

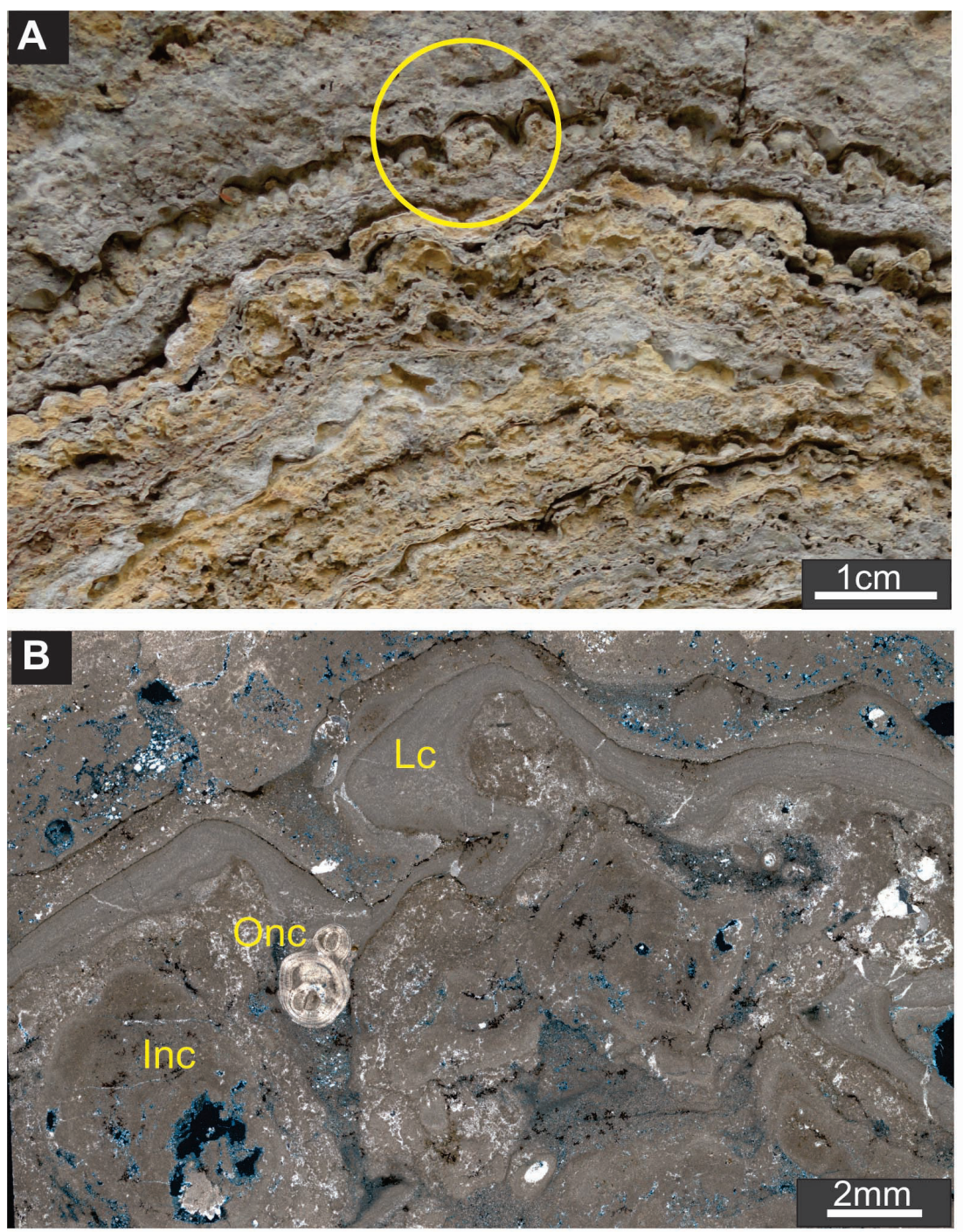

Figura 9. Microbialito Pseudo-microcolunar Aglutinante de micríta (MPMA-m). A) Aspecto geral macroscópico; B) Imagem petrográfica (com polarizador cruzado). Inc:Intraclastos (principalmente fragmentos de microbialitos com textura microgrumosa); Onc: oncólitos; Lc: laminação corrugada, formada pela aglutinação de micrita.

Figure 9. Micrite agglutinated, pseudo-microcolumnar microbialite (MPMA-m). A) General macroscopic view; B) Petrographic image (using cross polarized light). Inc: Intraclastics (mainly fragmented microbialite composed of microgrumous calcite; Onc: Oncolites; Lc: Wrinkled lamination structure formed by agglutination of micrite.

ram precitados quando foi incorporado à solução original ácido orgânico. Durante o estágio final da precipitação, observou-se, também, o início da formação das crostas de calcitas fasciculadas (Mercedes-Martín et al., 2016).

Ácidos orgânicos estão presentes no EPS (sacarídeos poliméricos extracelulares) das esteiras microbianas (Dittrich \& Sibler, 2010), portanto, atuam como catalizadores ativos do processo de mineralização de carbonatos nesses ambientes (Pedley, 1994; Arp et al., 1999), induzindo a formação dos esferulitos.

Na Sequência Balbuena IV, os esferulitos ocorrem no interior dos microbialitos, em meio à matriz microgrumosa recristalizada, possuem diâmetro de aproximadamente $200 \mu \mathrm{m}$, e, por vezes, ocorrem entre os esferulitos esparsos argilomi- nerais de esmectita autigênica (Fig. 13). Observa-se um sequenciamento desses elementos que apresentam textura fasciculada, iniciando com a formação dos esferulitos, evoluindo para cristal shrubs, e, por fim, às crostas. Segundo Verrecchia et al. (1995), os esferulitos podem originar também cristal shrubs, sendo observada a preciptação de esferulitos em meio as esteiras microbianas e a cristalização de crostas na superfície, vinculada aos períodos de exposição subaérea, durante os períodos de maior aridez.

Devido a esse sequenciamento e à característica da intrabioarquitetura MBFA-gf,esf, de ocorrer exclusivamente nos microbialitos da porção intermediária da Sequência Balbuena IV, posição na qual vigoraram as condições de maior aridez (Bento Freire, 2012; Bunevich, 2016), atribui-se que a 

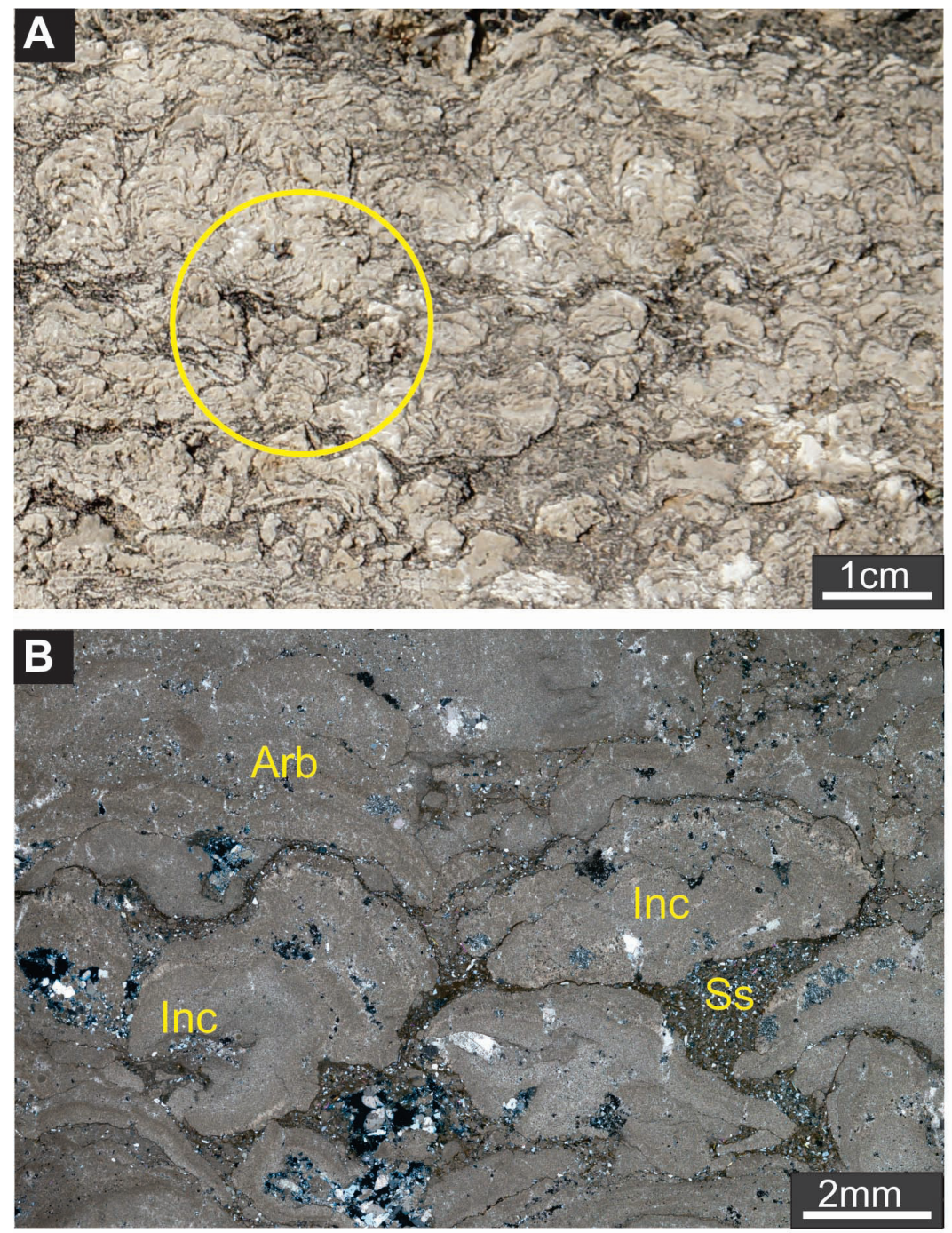

Figura 10. Microbialito Arbustiforme Microgrumoso Aglutinante de grão fino (MArbMA-gf). A) Aspecto geral macroscópico; B) Imagem petrográfica (com polarizador cruzado). Inc: sedimento intraclástico; Ss: Sedimento siltoso, composto por silte siliciclástico e mudstone; Arb: Estrutura arbustiforme com grande espalhamento lateral.

Figure 10. Fine grain agglutinated, grumous, shrubby microbialite (MArbMA-gf). A) General macroscopic view; B) Petrographic image (using cross polarized light). Inc: Intraclastics sediments; Ss: Silty sediment composed of siliciclastic silt and mudstone; Arb: Microbial shrub structure with large lateral spreading.

formação dos esferulitos ocorreu a partir de uma precipitação sindeposicional, sob influência orgânica, em função das condições do ambiente deposicional mais estressante.

\subsection{Estromatólito Microgrumoso/Aglutinante de grão grosso (EMA-gg)}

Caracteriza-se por apresentar estrutura laminada, com tendência em direção ao topo, a formar colunas. Essas estruturas são basicamente constituídas por calcita de textura microgrumosa e, em alguns níveis, de textura aglutinante (incorporando grãos de oncólitos e oólitos). Essas texturas são interpretadas como formadas tipicamente pela atividade microbial (Riding, 2011).

As fases de exposição registradas nesse tipo de intrabioarquitetura ocorrem pontuadas, por processos de dissolução. Portanto, pode-se dizer que durante os períodos de exposição ocorreu também o processo de dissolução por água meteórica (Fig. 14).

\section{Discussão dos resultados}

Conceitualmente, um ciclo sedimentar é definido como uma entidade, em uma dada escala, composta de uma série de elementos organizados no registro sedimentar, segundo um ordenamento lógico e que seja passível de ser reconhecido devido à sua repetitividade, mesmo que a série encontre-se incompleta (modif. de Schwarzacher, 1993). Esses elementos podem ser: texturas, fácies, associações de fácies, elementos arquiteturais, padrão de empilhamento (espessamento ou afinamento 

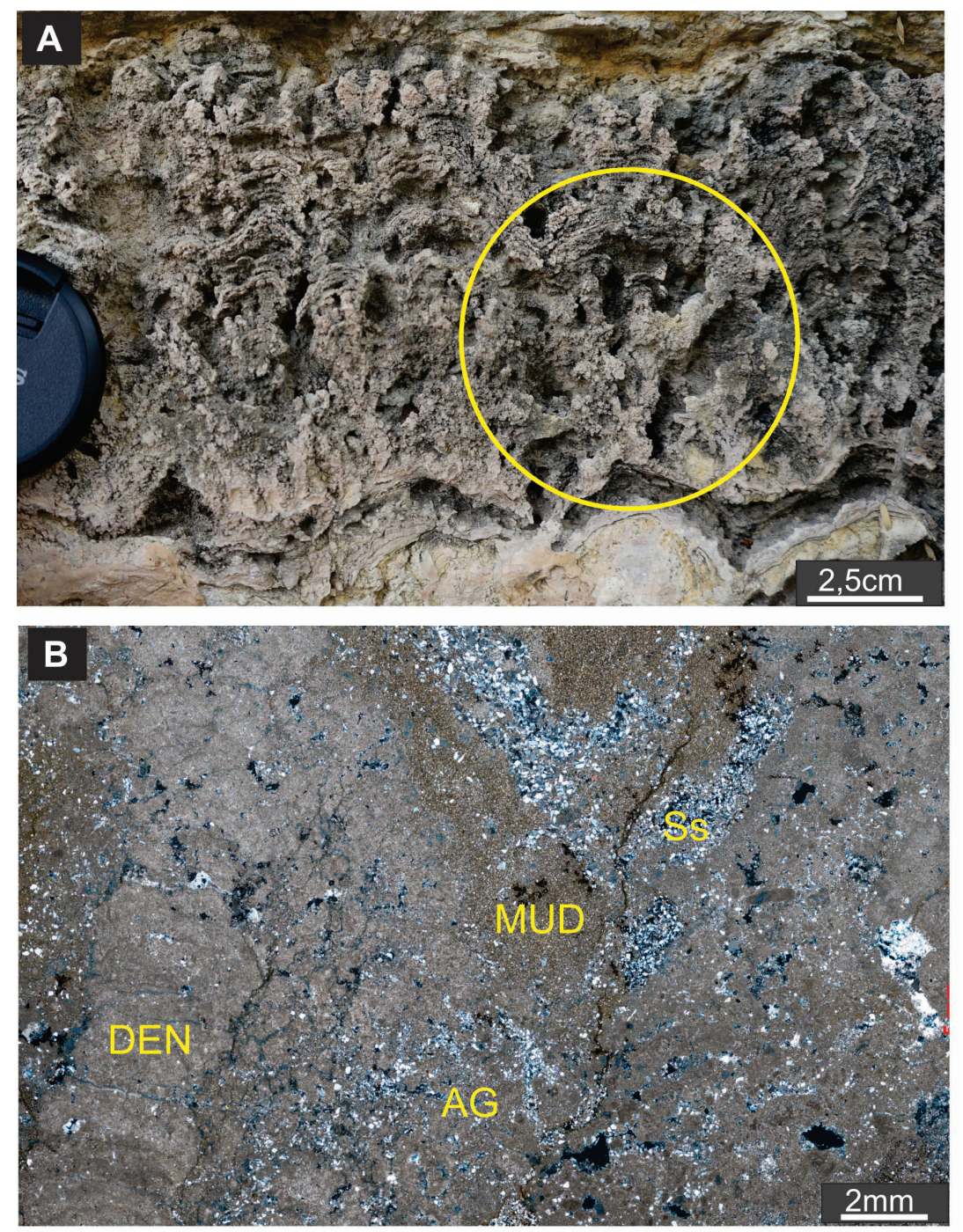

Figura 11. Microbialito Dendriforme Microgrumoso Aglutinante de grão fino (MDMA-gf). A) Aspecto geral macroscópico; B) Imagem petrográfica (com polarizador cruzado). DEN: corresponde a colunas dendriformes formadas de calcita microgrumosa; AG: Sedimento fino aglutinado (pelóides, oólitos e silte siliciclástico); MUD: Mudstone; Ss: Sedimento siltoso composto por quartzo e feldspato.

Figure 11. Fine grain agglutinated, grumous dendriform microbialite (MDMA-gf). A) General macroscopic view; B) Petrographic image (using cross polarized light). DEN: dendritic columns formed by microgrumous calcite; AG: fine binded grains (ooliths, peloids and siliciclastic silt); MUD: Mudstone; Ss: Silty sediment composed of quartz and feldspar.

das camadas), etc.

Neste trabalho, os padrões intrabioarquiteturais apresentam uma organização em escala mesoscópica, na qual se reconhecem superfícies (de expansão e retração do lago), bem como a alternância de estruturas e de texturas que denotam um controle cíclico com certa repetitividade, resultantes das variações climáticas, que controlam o espaço de acomodação, tendo reflexo também nas variações do volume de água e, portanto, na saturação de íons no lago.

Dessa forma, o padrão intrabioarquitetural pode corresponder ao elemento básico que caracteriza o padrão de ciclicidade. Apesar de reconhecido em escala mesoscópica, pode ser definido com maior confiabilidade, quanto a sua organiza- ção e os tipos de elementos que o compõem, na escala microscópica. Portanto, essa seria a escala que confirma a existência desses padrões de ciclicidade, os quais serão denominados neste trabalho de microciclos.

Em microescala, os sete padrões intrabioarquiteturais identificados apresentam características comuns e, portanto, é possível associá-los a três tipos de microciclos.

Os microciclos, que serão discutidos nos próximos itens, quando agrupados, também permitem definir tendências em escala mesoscópica. 0 empilhamento desses microciclos evidencia padrões de adelgaçamento e de espessamento, que estariam vinculados a uma outra hierarquia de menor ordem de análise cicloestratigráfica (Bune- 

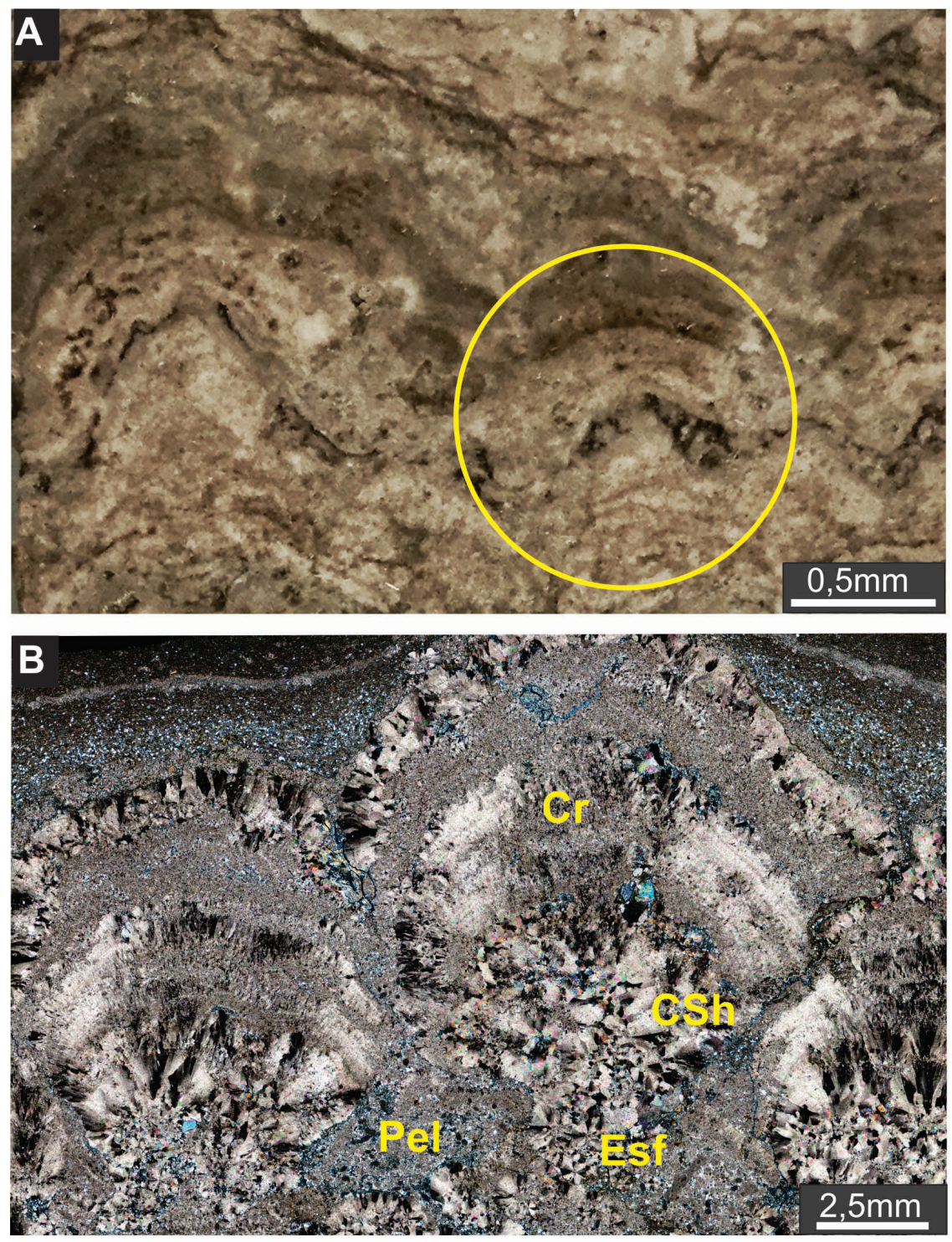

Figura 12. Microbialito Bandeado Fasciculado/Aglutinante de grão fino com esferulito (MBFA-gf,esf). A) Aspecto geral macroscópico; B) Imagem petrográfica (com polarizador cruzado). Esf: esferulitos; CSh: Cristal shrubs formados de calcita fasciculada; Pel: Pelóides; Cr: Crostas fasciculadas

Figure 12. Fine grain agglutinated with esferulites, sparite fan, banded microbialite (MBFA-gf,esf). A) General macroscopic view; B) Petrographic image (using cross polarized light). Esf: spherulites; CSh: Crystal shrubs; Pel: Peloids; Cr: Sparite fan crusts.

vich, 2016) a qual não será tratada neste trabalho.

\subsection{Microciclos tipo I}

O microciclo tipo I ocorre nas seguintes intrabioarquiteturas: Microbialito Aglutinante de grão grosso (MA-gg); Microbialito Pseudo-microcolunar Aglutinante de micrita (MPMA-m); Microbialito Arbustiforme Microgrumoso Aglutinante de grão fino (MArbMA-gf); Microbialito Dendriforme Microgrumoso Aglutinante de grão fino (MDMA-gf); Estromatólito Microgrumoso/Aglutinante de grão grosso (EMA-gg).

As intrabioarquiteturas exibem em comum, estruturas internas laminadas ou microcolunares formadas por calcita de textura microgrumosa ou aglutinante de micrita. Entre essas estruturas, de- positam-se partículas de pelóides, oólitos, oncólitos, intraclastos e também de sedimento siliciclástico na granulometria silte - areia fina. A figura 15 apresenta a interpretação dos microciclos, sendo representados pelos triângulos de Karagodin e limitados pelas superfícies de exposição (SE).Os limites desses microciclos podem ser reconhecidos também em mesoescala a partir das superfícies de exposição e das mudanças das texturas internas, conforme ilustrado na figura 16.

Como pode ser observado na figura $16 \mathrm{~A}$, em mesoescala, existe uma organização cíclica marcada pela alternância de níveis com textura lisa (laminada) e rugosa (irregular). Essa diferenciação também está limitada por feições de exposição, determinadas em escala microscópica na figura 16C. Utilizando esses critérios, o microbialito pode ser compartimentado em microciclos. A partir do 

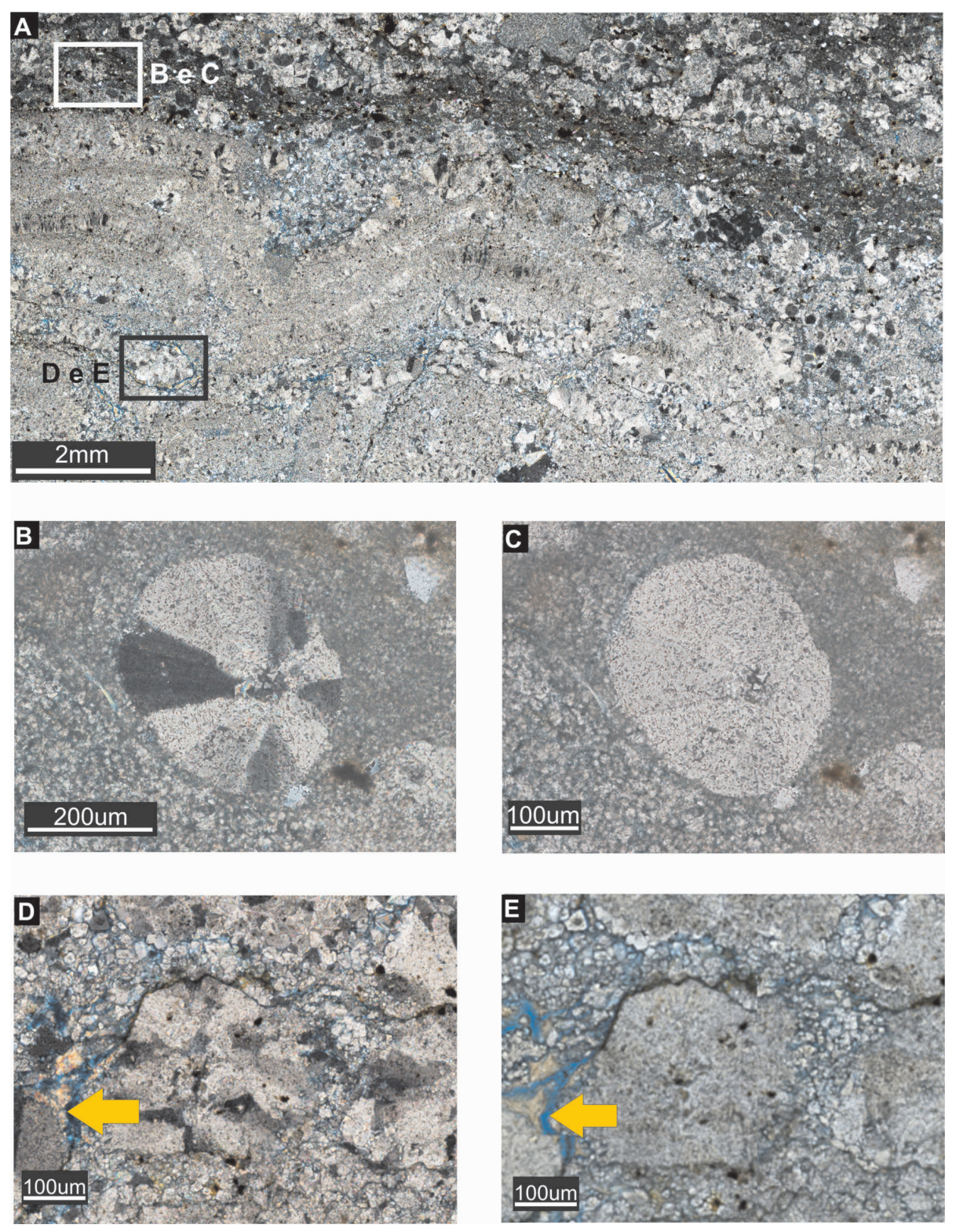

Figura 13. Forma de ocorrência dos esferulitos. A) Visão geral; B e C) Detalhes de esferulitos em meio a sedimento retrabalhado, com matriz argilosa (usando polarizador cruzado e paralelo, respectivamente); D e E) Detalhe de esferulitos desenvolvidos entre as estruturas microbiais (usando polarizador cruzado e paralelo, respectivamente). A seta indica a ocorrência de porosidade associada à esmectita, provavelmente resultante da retração do argilomineral.

Figure 13. Form of occurrence of spherulites. A) General view; B and C) Detail of spherulites in reworked sediment with clayey matrix;(using cross and plane polarized light, respectively); $D$ and E) Detail of spherulites developed inside microbial structures (using cross and plane polarized light, respectively, the arrow indicates the porosity associated with smectite, probably as a result of retraction of the claymineral.

empilhamento dos microciclos pode-se verificar a tendência de thinning, bem como a maior recorrência das feições de exposição em direção ao topo do microbialito (Fig. 16A), que pode ser interpretado devido a uma diminuição do espaço de acomodação progressiva, associada a uma maior frequência das exposições.

\subsection{Microciclos tipo II}

O microciclo tipo II ocorre exclusivamente na intrabioarquitetura, Microbialito Bandado Fasci-
culado/Aglutinante de grão fino (MBFA-gf). No registro alternam-se bandas de diferentes texturas. As microestruturas colunares (de textura microgrumosa) com espaço intercolunar preenchido por oólitos e pelóides, são bastante parecidas em termos de organização com os elementos do ciclo tipo I. Diferem-se basicamente por dois quesitos: o baixo conteúdo de silte siliciclástico (indicando menor aporte de terrígenos) e a formação de crostas de calcita com textura fasciculada, com pouca evidência de feições de erosão e de dissolução.

Dessa forma, a posição final do microciclo re- 

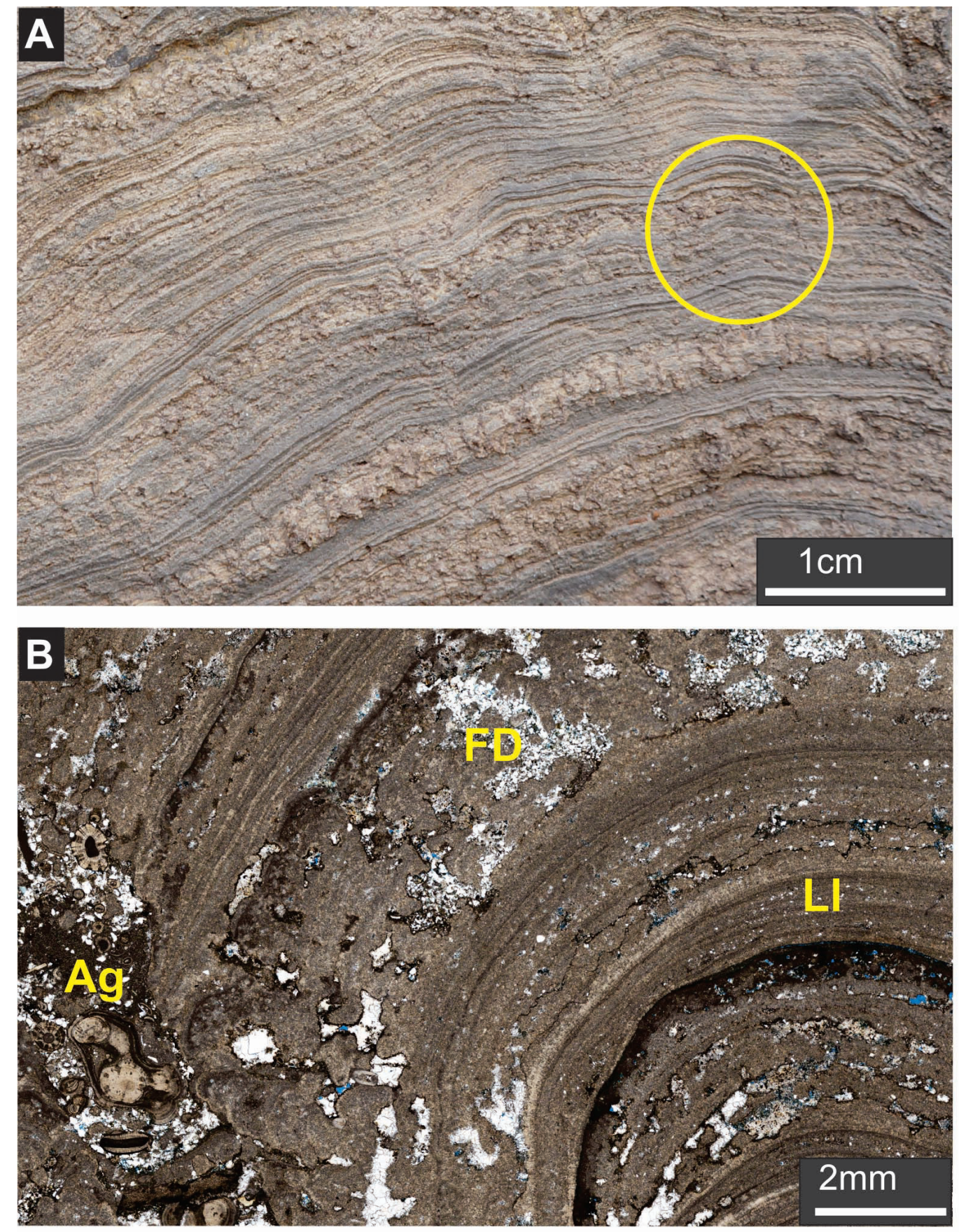

Figura 14. Estromatólito Microgrumoso/Aglutinante de grão grosso (EMA-gg). A) Feição macroscópica; B) Imagem petrográfica (com polarizador cruzado). Ll: estrutura laminada formada por calcita microgrumosa; FD: Feições de dissolução preenchidas por cimentos e sedimento fino composto por silte siliciclástico; Ag: Sedimentos aglutinados (oncólitos, silte e mudstone).

Figure 14. Coarse grain agglutinated, microgrumous, stromatolite (EMA-gg). A) General macroscopic view; B) Petrographic image (using cross polarized light). Ll: Laminated structure formed by microgrumous calcite; FD: Dissolution features filled with cement and fine sediment composed mainly of siliciclastic silt; Ag: Trapped sediments (oncolites, silt and mudstone).

gressivo foi marcada no topo das crostas fasciculadas. Nesse caso, interpreta-se que, devido a um processo evaporativo, a concentração de carbonato de cálcio na água do lago tende a aumentar gradualmente tornando as condições favoráveis para a precipitação da calcita fasciculada. Essa feição marcaria as fases de maior aridez (Fig. 17).

Na figura 18 A é apresentada a interpretação de microciclos em um microbialito com a morfologia tabular, na qual se pode verificar uma compartimentação textural, marcada pela alternância de níveis com textura lisa (de cor acinzentada) que corresponde aos níveis de crostas de calcita com textura fasciculada. Os demais níveis ou bandas com maior porosidade correspondem aos níveis nos quais predominam as calcitas de textura 


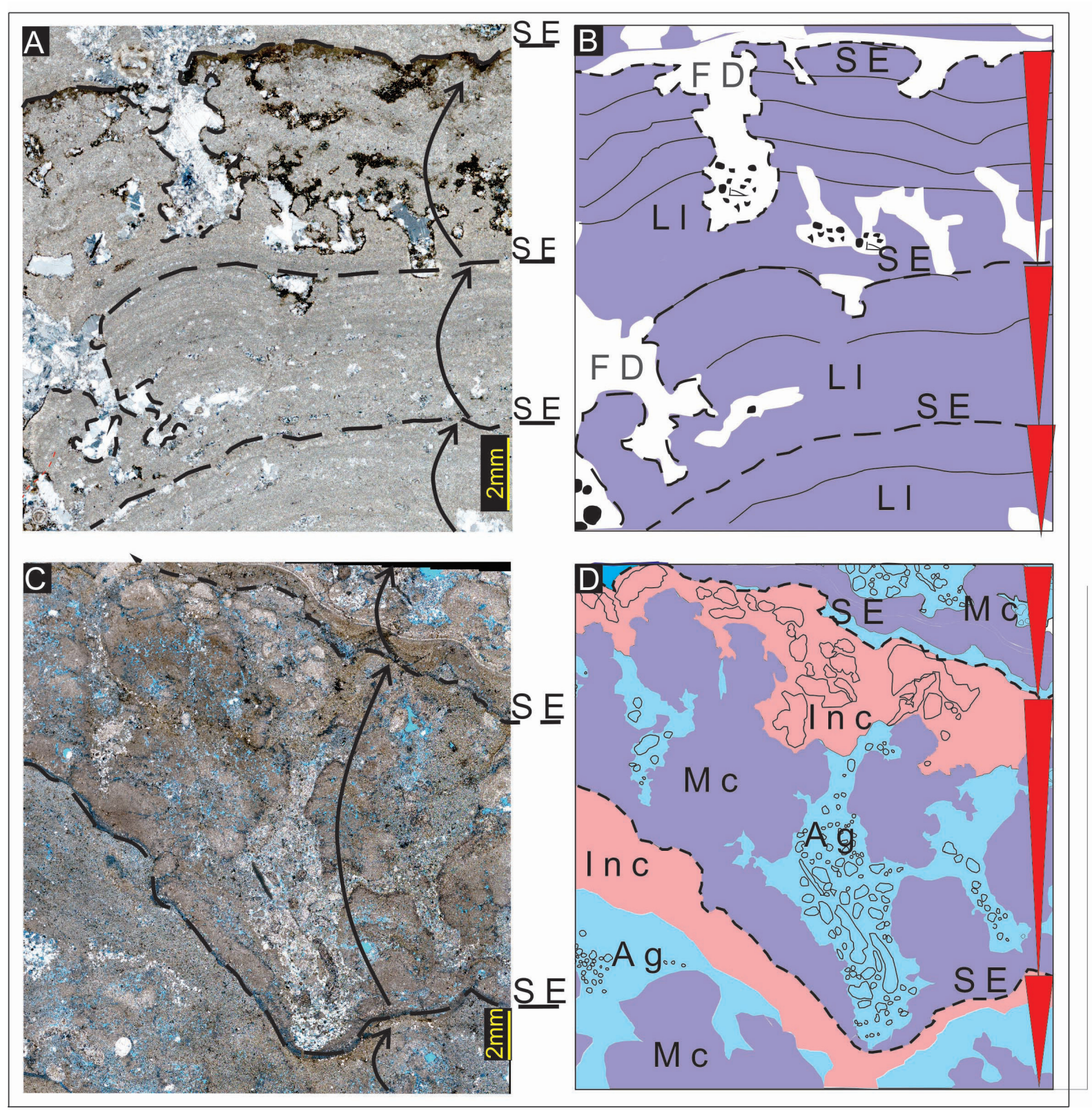

Figura 15. Fotomicrografias com exemplos de recorrência do ciclo elementar tipo I. A) Microbialito Microgrumoso/Aglutinante de grão grosso (MA-gg), as posições dos microciclos regressivos estão pontuadas por eventos de exposição. Ll: Estruturas laminadas com textura microgrumosa; FD: Feições de dissolução preenchidas por sedimento siliciclástico, oólitos e cimento espáticos; C) Microbialito Dendriforme Microgrumoso Aglutinante de grão fino (MDMA-gf), a posição final dos ciclos regressivos é pontuada por superfícies de exposição (SE). Mc: Microcolunas com textura microgrumosa; Ag: Sedimento aglutinado (siliciclástico + oólitos e intraclastos); Inc: Intraclastos de sedimento microbial fragmentado; B e D) Imagens esquemáticas representando a organização dos microciclos.

Figure 15. Photomicrographies presenting examples of recurrence of elementary cycle type I. A) Coarse grain agglutinated, microgrumous, microbialite (MA-gg), the position of regressive cycles is punctuated by exposition events. Ll: Laminated structures with microgrumous texture; FD: Dissolution features filled with siliciclastic sediment, oolites and spathic cement; C) Fine grain agglutinated microgrumous, dendriform microbialite (MDMA-gf), the final position of regressive cycles are punctuated by exposition surfaces (SE). Mc: Microcolumns with microgrumous texture; Ag: Trapped sediments (siliciclastic sediment + oolites and intraclastics); Inc: Microbial sediment crackled; B and D) Schematic pictures representing the microcycles organization.

microgrumosa. Essa organização cíclica pode ser confirmada em escala microscópica na figura $18 \mathrm{~B}$.

Em mesoescala (Fig $18 \mathrm{~A}$ ), o registro microbial, ao ser dividido em microciclos, pode verificar se a tendência de thinning e o predomínio das calcitas de textura fasciculadas em direção ao topo, são características possivelmente relacionadas às condições crescentes de aridez.

\subsection{Microciclos tipo III}

O microciclo tipo III ocorre exclusivamente na intrabioarquitetura Microbialito Bandado Fas- 


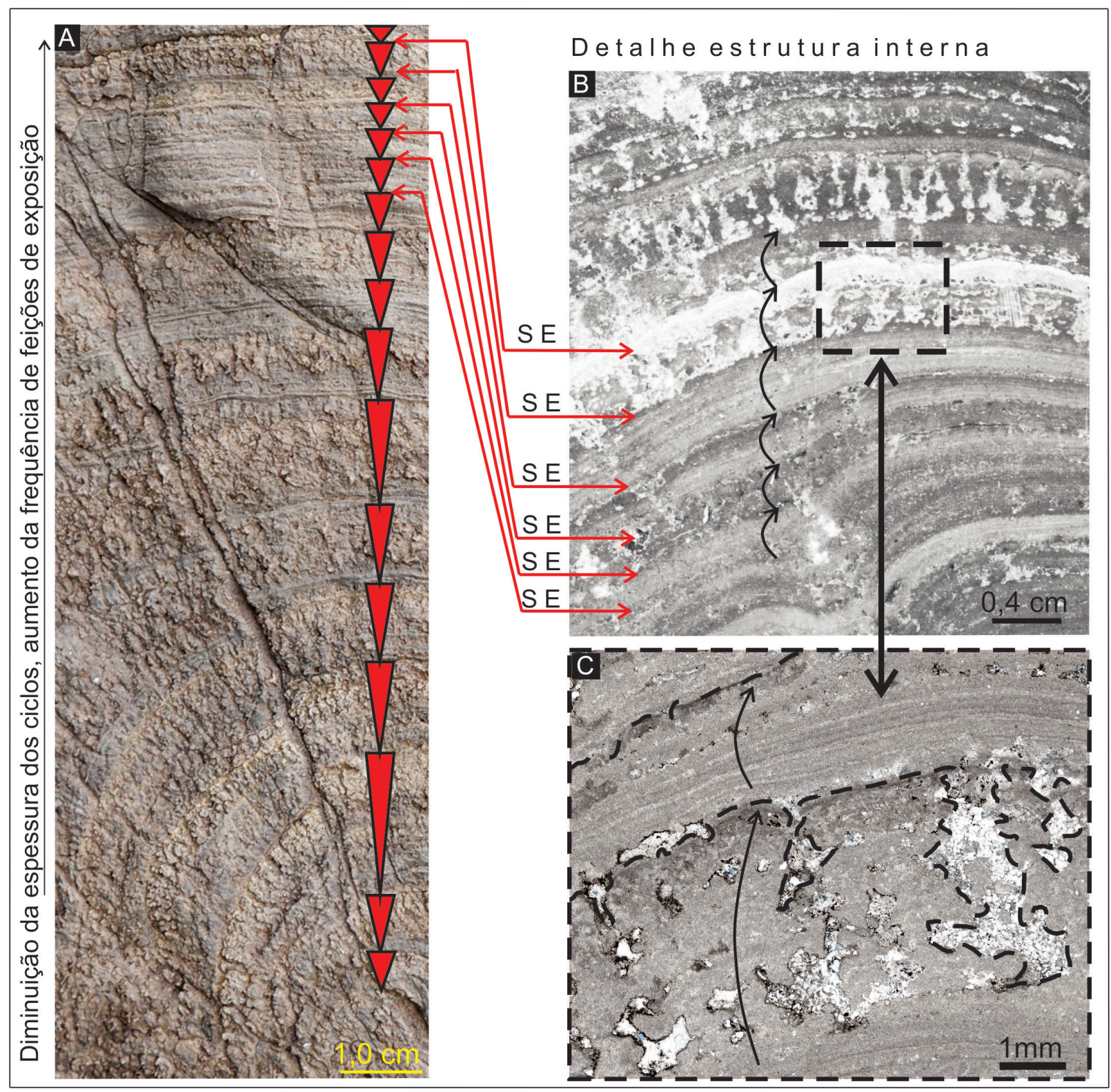

Figura 16. Compartimentação dos microciclos tipo I em estromatólito com morfologia dômica. A) Posição dos microciclos; B) Detalhe dos intervalos com estruturas laminadas marcando comportamento cíclico; C) Imagem petrográfica (usando polarizador cruzado) exibindo feição de exposição com preenchimento por areia muito fina. SE: Superfície de exposição.

Figure 16. Compartmentalization using microcycles type I in stromatolite with dome-morphology. A) Position of microcycles; B) Details of intervals with laminated structures indicating cyclical behavior; C) And petrographic image (using cross polarized light) showing exposure features filled up with very fine sand. SE: Exposition surface.

ciculado/Aglutinante de grão fino com esferulito (MBFA-gf,esf). Esse microciclo possui elementos semelhantes àqueles do tipo II, que são caracterizados pela presença de esferulitos ou de estruturas do tipo cristal shrubs, que evoluem para crostas de textura fasciculada. Esses elementos foram utilizados como marcadores das superfícies de exposição (SE) ou superfícies de maior aridez (Fig. 19).

A figura 20 A apresenta o intervalo de um microbialito com morfologia planar ou estratiforme, na qual há (em mesoescala) um thinning dos microciclos na transição de estruturas colunares para laminadas e, posteriormente, um thickening, voltando a ocorrer estruturas colunares em dire- ção ao topo.

Essas mudanças de tendências possivelmente refletem variações no espaço de acomodação, interpretação corroborada também pela presença de mudstone, no topo do microbialito, o que indica a direção da tendência transgressiva e, portanto, de aumento de espaço de acomodação. Na figura $20 \mathrm{~B}$ é apresentado o detalhe das crostas pontuando o final dos microciclos em escala microscoópica.

\subsection{Ocorrência de argilas}

Outro elemento acessório frequente são as esmectitas, que ocorrem tanto nos microciclos 


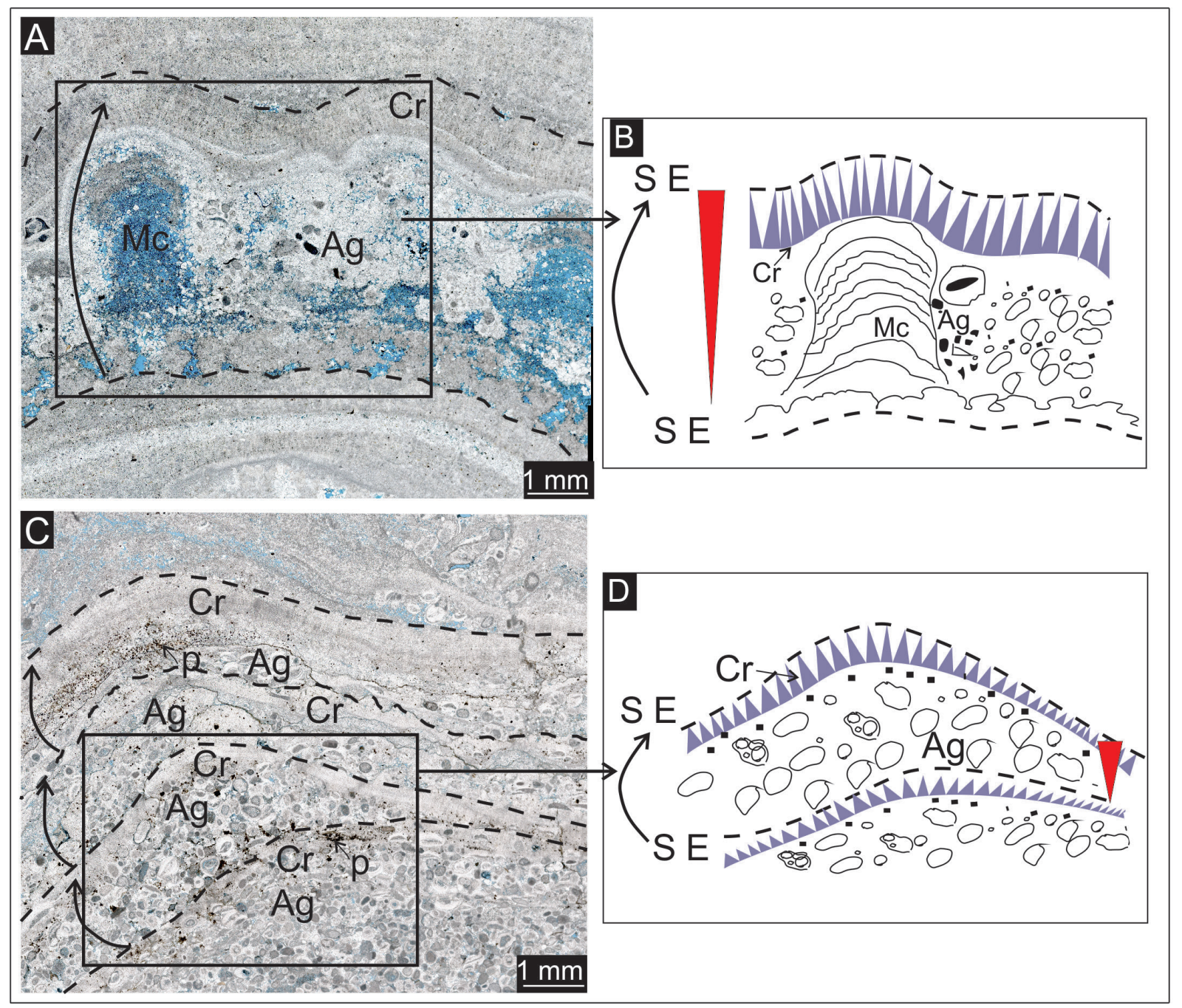

Figura 17. Exemplos de ocorrência dos microciclos do tipo II, em Microbialito Bandado Fasciculado/Aglutinante de grão fino (MBFA-gf), a posição final dos microciclos está pontuada pela presença de crostas de calcita com textura fasciculada. A) Intervalo com predomínio da estrutura microcolunar, composta de calcita microgrumosa; C) Intervalo com predomínio da estrutura laminada com textura aglutinante de grão fino. Mc: Microcolunas de calcita microgrumosa laminada; Cr: Crosta de calcita fasciculada; Ag: Sedimento aglutinado (oólito, oncólito e silte); p: Pirita; SE - Superfície de exposição; B e D) Imagens esquemáticas representando os microciclos.

Figure 17. Examples of occurrence of microcycles type II, in fine grain agglutinated and sparite fan crust, banded microbialite (MBFA-gf), the position of regressive cycles are punctuated by the development of sparite fan crust. A) Interval with predominance of microcolumnar structure composed by microgrumous calcite; C) Interval with predominance of laminated structure, composed by fine grain agglutinated texture. Mc: Laminated microcolumn composed by microgrumous calcite; Cr: Sparite fan crust; Ag: Trapped sediments (oolites, oncolites and siliciclastic silt); p: Pyrite; SE - Exposition surface; B and D) Schematic pictures representing the microcycles.

tipo II como nos tipo III. Neste trabalho, a gênese desses argilominerais foi interpretada como sendo condicionada ao aumento de umidade. Gomes (2013), por meio de análises de difração de raios $\mathrm{X}$, nos intervalos onde ocorrem microbialitos formados por microciclos tipo II e III, caracterizou a presença de esmectita (discreta, bem cristalizada) e de ilíta (também com boa cristalinidade). Como essas argilas ocorrem em meio à laminação, sugere-se que a precipitação ocorreu na superfície do microbialito durante a formação do depósito (Fig. 21). Os resultados da difração de raios-X dão suporte à interpretação da origem singenética precoce dessas argilas.
Essas argilas frequentemente exibem porosidade entre suas estruturas lamelares, cuja porosidade é interpretada como produto da perda de água por desidratação, já que as esmectitas apresentam como característica a elevada expansibilidade quando hidratadas.

\subsection{Relação entre microciclos}

Os microciclos definidos como tipos I, II e III correspondem àqueles de mais alta frequência, que conduzem à formação dos microbialitos lacustres, em condições ambientais de raseamento, com 


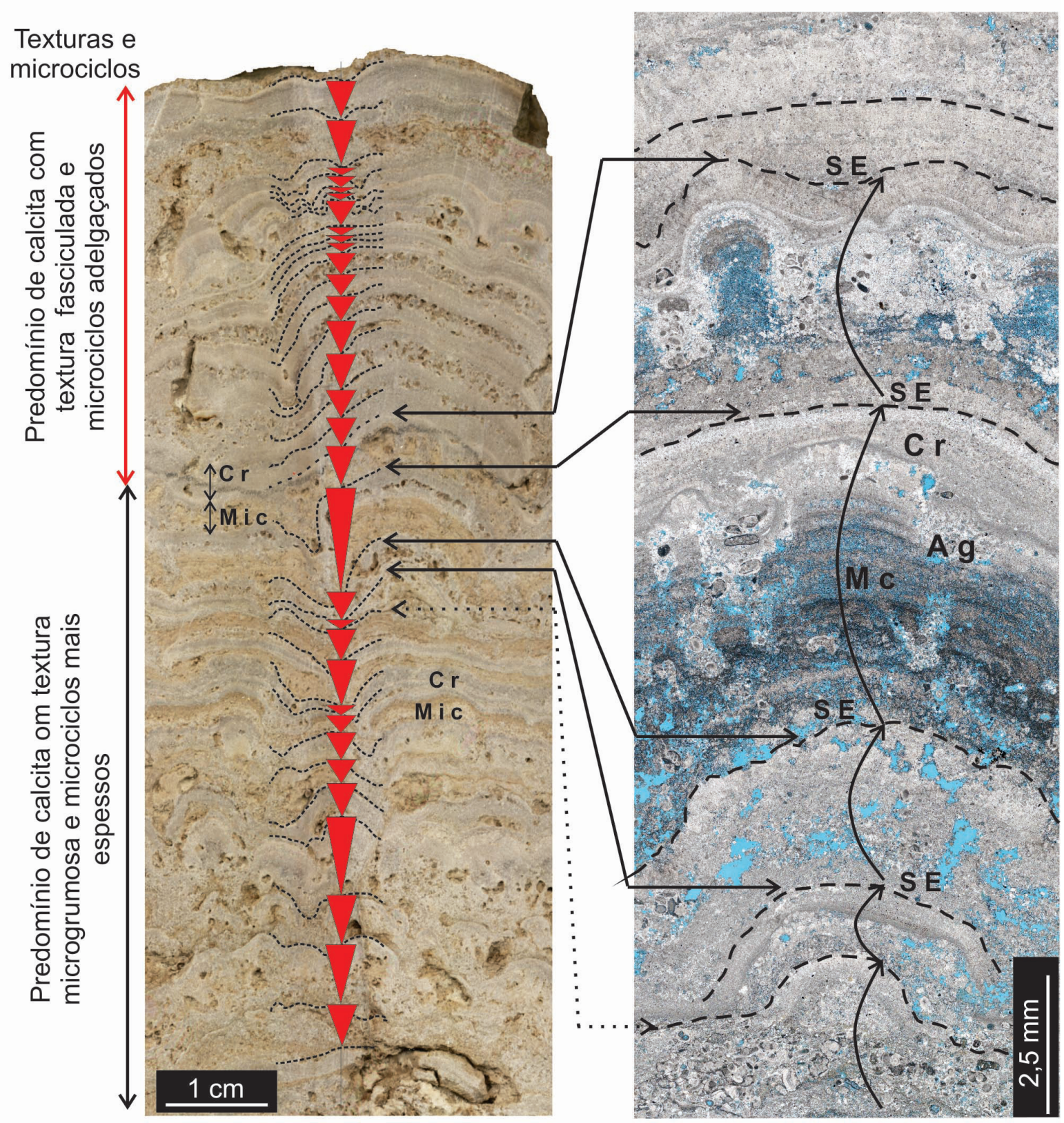

Figura 18. Compartimentação dos microciclos tipo II em microbialito tabular. A) Alternância de crostas de calcita (Cr) com intervalos de texturas típicas microbiais (Mic); B) Comportamento cíclico do depósito em escala microscópica. Mc: Microcolunas microgrumosas; Ag: Sedimento aglutinado (oólitos e pelóides); Cr: Crostas fasciculadas; SE- Superfície de exposição.

Figure 18. Compartmentalization of microcycles type II in tabular microbialite. A) Alternation crust calcite (Cr) with intervals of typical microbial textures (Mic); B) Cyclic behavior of the deposit in microscopic scale. Mc: Microgrumous microcolumns; Ag: Trapped granular sediment (oolites and peloids); Cr: Crusts; SE- Exposition surface.

maior ou menor estresse ambiental. Entende-se por fator de estresse ambiental o aumento da concentração de sais na água e a exposição subaérea.

Devido principalmente à atuação desses fatores, são produzidos os diferentes elementos, texturas e estruturas discutidos neste trabalho. No entanto, também existem situações onde os microbialitos podem se formar durante o início de uma fase transgressiva, ou seja, de expansão do lago (Fig. 22 A e B), deixando assim, registradas no microbialito, as mudanças de texturas e estruturas decorrentes da tendência dominantemente positiva de variação do nível de base.

Esses microciclos são menos comuns em relação àqueles formados durante o raseamento. Isso ocorre devido à baixa taxa de desenvolvimento dos microbialitos, durante o rápido aumento da lâmina d'água. Nessa fase, também ocorre o maior aporte de sedimentos, que promove a inibição e, posteriormente, o soterramento das colônias microbiais por sedimentos finos (mudstone e silte siliciclástico). 

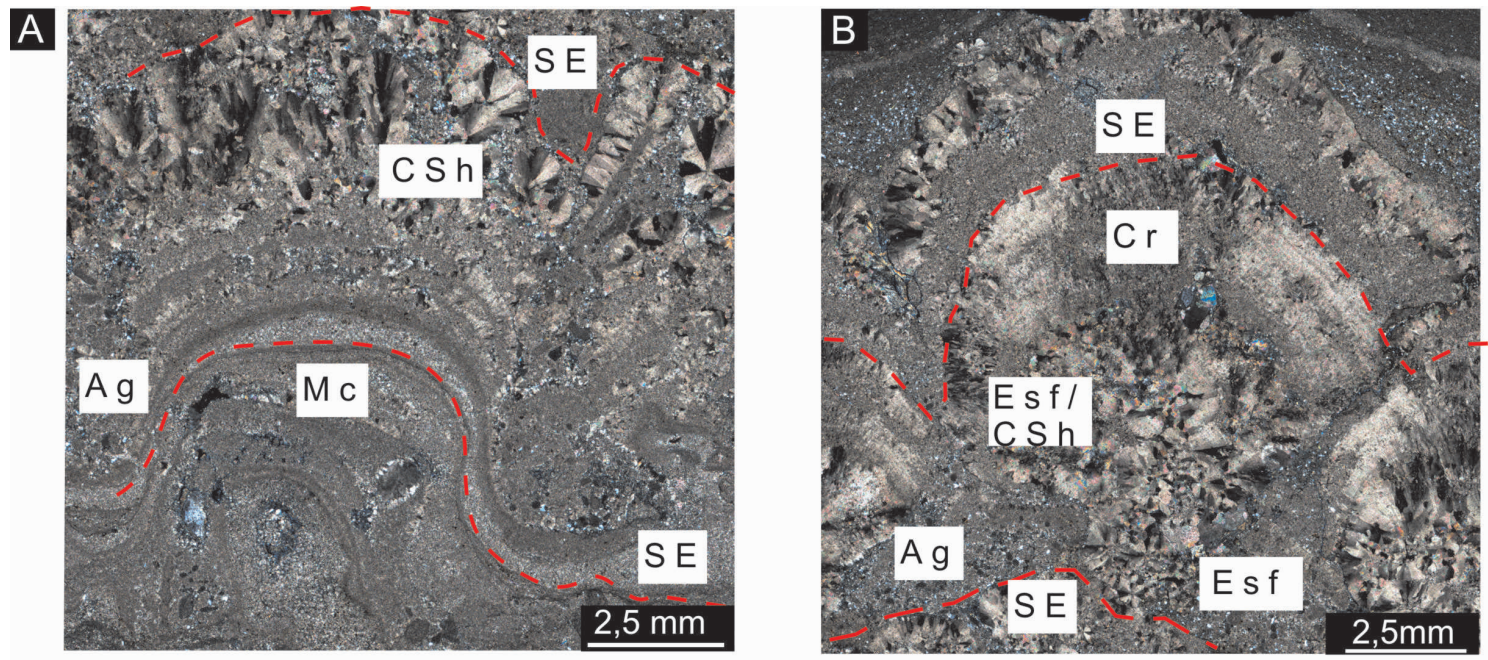

C
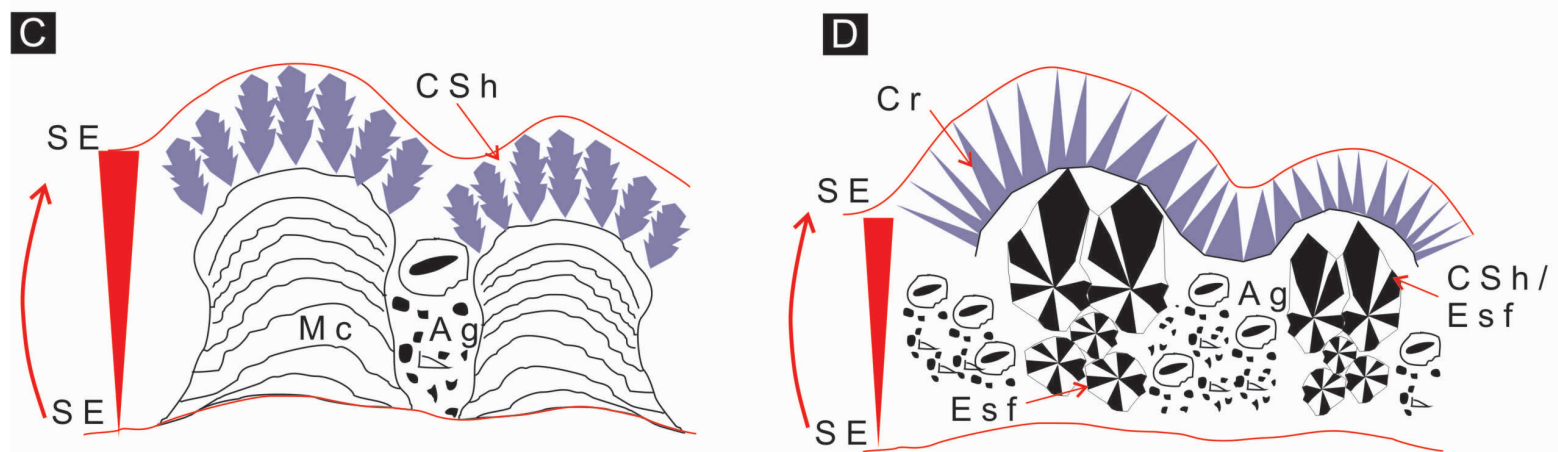

Figura 19. Exemplos de organização do microciclo tipo III. A) Interpretação dos microciclos tipo III em microbialito com cristal shrub; B) Interpretação dos microciclos tipo III em microbialito com esferulitos e crostas. Mc: Microcolunas de calcita microgrumosa; CSh: Cristal shrub; Esf: Esferulito; Esf/ CSh: Esferulito passando para cristal shrub; Cr: Crosta; Ag: Sedimento aglutinado (oólito, oncólito e silte); SE: Superfície de exposição; C e D) Representações esquemáticas dos microciclos.

Figure 19. Examples of microcycles type III organization; A) Interpretation of type III microcycles in microbialite with crystal shrub; B) Interpretation of type III microcycles in microbialite with spherulites and crusts. Mc: Microcolumn composed by microgrumous calcite; CSh: Crystal shrub; Esf: Spherulite; Esf / CSh: Spherulite to crystal shrub; Cr: Sparite fan crust; Ag: Trapped sediments (oolites, oncolites and siliciclastic silt); SE: Exposition surface; C and D) Schematic pictures of microcycles.

De forma a relacionar esquematicamente a formação dos microbialitos em função do clima, e do nível de base do lago, a figura 23 sintetiza em uma curva os principais produtos formados em cada estágio, os quais devem ser considerados na análise sequencial de cada microciclo: tipos de grãos aglutinados (apresentados acima da linha pontilhada até a parte superior da curva); estruturas e texturas que formam o arcabouço microbial (apresentados abaixo da linha pontilhada até a parte inferior da curva); e, por fim, as feições que indicam o tipo de superfície, as quais caracterizam os limites regressivos e transgressivos de cada ciclo (apresentadas na porção central e à direita do diagrama).

\section{Conclusões}

Os microbialitos da Sequência Balbuena IV exibem grande diversidade de morfologias em mega- e macroescala. A caracterização em meso- e microescala resultou na identificação de sete tipos de intrabioarquiteturas, as quais apresentam um sequenciamento de elementos, que caracterizam os microciclos. Esse ordenamento possibilitou a organização interna e o entendimento do processo de formação do depósito microbial.

Num contexto de retração do nível de base do lago, os microciclos foram divididos em três tipos formados a partir de condições climáticas de aridez crescente, sendo as do tipo I o menos árido, as do tipo II intermediário e as do tipo III o mais árido. Esses microciclos diferem entre si de acordo com o tipo de partículas aglutinadas e da textura e estrutura da calcita que forma arcabouço do microbialito.

No contexto de retração, considerando o microciclo tipo I, a fábrica microbial é favorecida, exibindo texturas predominantemente microgrumosa e aglutinante (de grãos carbonáticos e principalmente de siliciclásticos), com frequentes feições de dissolução e de erosão que denotam as superfícies regressivas. Os microciclos tipos II e 
A

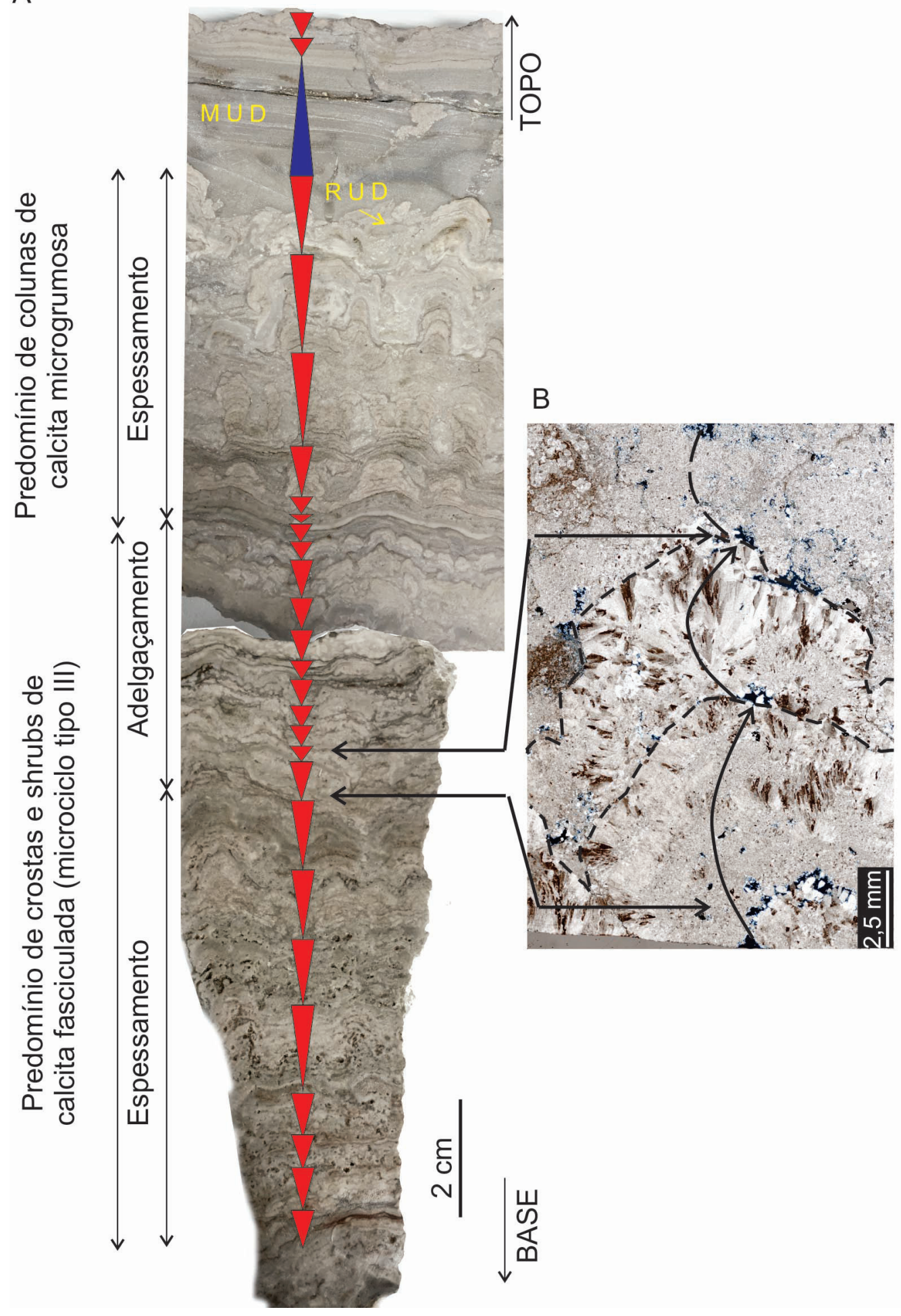

Figura 20. Microciclos do tipo III, em microbialito com morfologia planar. A) Estruturas microcolunares exibindo adelgaçamento dos microciclos em direção ao topo e predomínio de calcita com textura fasciculada e esferulitos da base até a porção central do microbialito. Da porção central até o topo do microbialito, os microciclos exibem uma tendência de espessamento, associado a um maior desenvolvimento de estruturas colunares e textura microgrumosa; B) Fotomicrografia (com polarizador cruzado) exibindo as crostas de calcita pontuando o final dos microciclos tipo III.

Figure 20 - Microcycles type III in microbiolite with planar morphology. A) Microcolumnar structure shows a thinning upward trend of microcycles and the predominance of calcite with sparite fan crust and spherulites from the base to the middle part of microbialite; from the middle part to the top of microbialite, the microcycles exhibit a thickening upward trend, combined to a higher development of columnar structure with microgrumous textures; B) Photomicrography (using cross polarized light) showing calcite sparite fan crust punctuating the microcycles type III. 

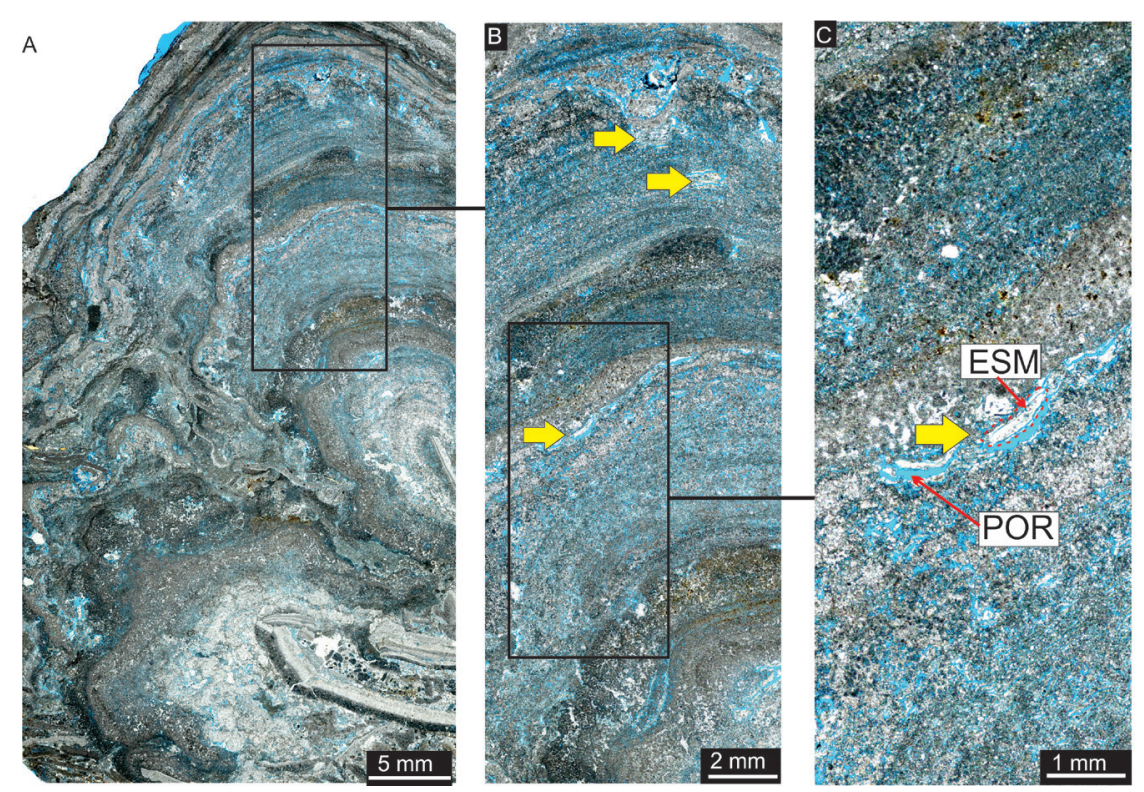

Figura 21. Microbialito com esmectitas. A) Visão geral do microbialito; B e C) Imagens ampliadas, nas quais as setas brancas mostram a posição onde ocorre a esmectita (ESM), normalmente acompanhando a laminação do microbialito e associada à ocorrência de porosidade (POR).

Figure 21. Microbialite with smectite. A) Overview of microbialite; $B$ and C) Detailed images, where white arrows show the smectite (ESM) position, usually following the microbialite lamination and associated with porosity (POR).
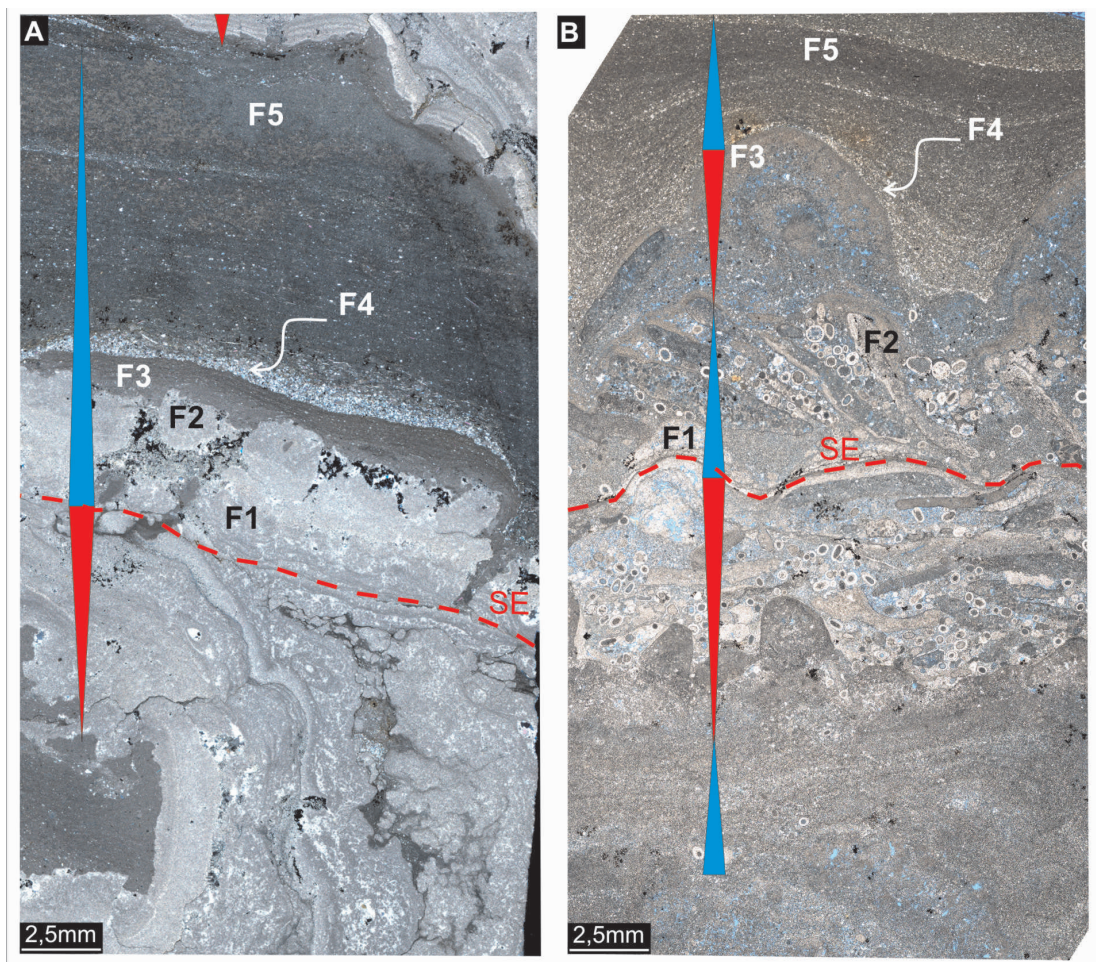

Figura 22. Exemplos de registro de microciclos transgressivos em dois microbialitos (A e B), apresentando o mesmo ordenamento de processos e produtos por fase. F1: Desenvolvimento de microbialito (microgrumoso); F2: Retrabalhamento de sedimentos durante a subida do nível de base; F3: Retomada da atividade microbial; F4: Formação de microbialito aglutinante de siliciclásticos finos (silte e micas); F5: Registro transgressivo final (mudstone e argilominerais).

Figure 22. Examples of transgressive microcycles in microbialites ( $A$ and B), presenting the same sequencing of processes and products by phase. F1: Development of microbialite (microgrumous); F2: Reworked sediment during the rise of the base level; F3: Microbial sediments recovering; F4: Development of fine siliciclastic agglutinated microbialite (silt and mica); F5: Final transgressive record (mudstone and clay). 


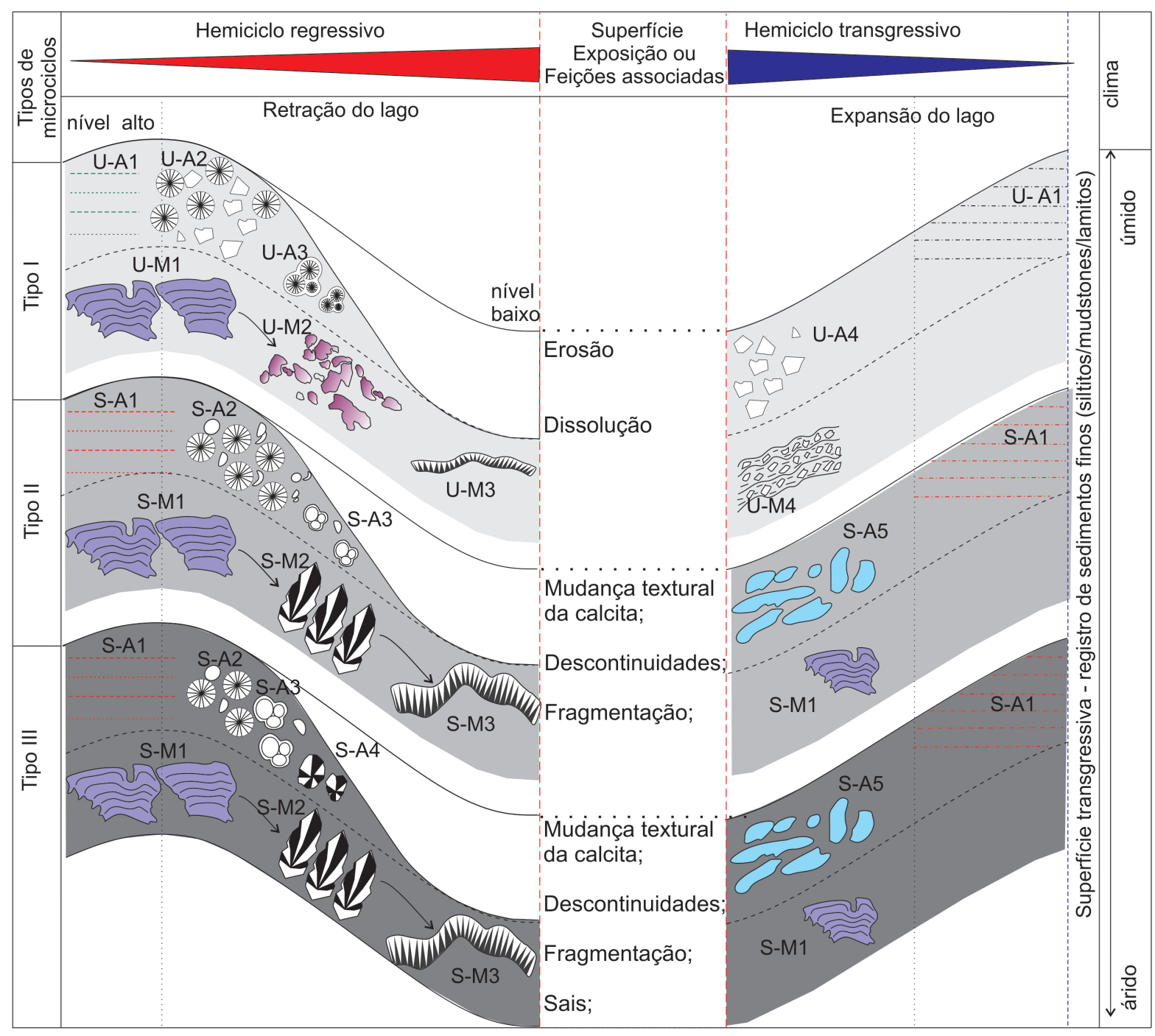

Figura 23. Relações entre os microciclos tipos I, II e III. U-A1:Argilominerais (detríticos); U-A2: Oólitos e areia fina; U-A3: Oncólitos; U-A4: Areia fina; U-M1: Estruturas microcolunares de textura microgrumosa; U-M2: Fragmentos de microbialito; U-M3: Crostas pouco desenvolvidas; U-M4: Microbialito aglutinante de siliciclásticos; S-A1: Argilominerais autigênicos (esmectitas); S-A2: Oólitos e pelóides; S-A3: Grapestones e oncólitos; S-A4: Esferulitos; S-A5: Fragmentos retrabalhados diversos; S-M1: Estruturas microcolunares de textura microgrumosa; S-M2: Shrubs de calcita fasciculada; S-M3: Crostas bem desenvolvidas. Nas três curvas, a linha pontilhada preta separa os elementos não ligados (acima), dos ligados (abaixo).

Figure 23. Relationship between microcycles type I, II and III. U-A1: Clay (detrital); U-A2: Oolites and fine sand; U-A3: Oncolites; U-A4: Fine sand; U-M1: Microcolumnar structures with microgrumous texture; U-M2: Crackle fragments of microbialite; U-M3: Sparite fan crusts; U-M4: Fine grain siliciclastic agglutinated microbialite; S-A1: Autigenic clay minerals (smectite); S-A2: Oolites and peloids; S-A3: Grapestones and oncolites; S-A4: Spherulites; S-A5: Reworked fragments; S-M1: Microcolumnar structures with microgrumous texture; S-M2: Cristal Shrubs; S-M3: Sparite fan crusts well developed. In all three curves, the dotted black line separates unbound components (above) from the bound components (below).

III favorecem a formação das calcitas fasciculadas, possivelmente pelo aumento da concentração de carbonato de cálcio na água. Na fase aglutinante predominam os oólitos e sedimentos carbonáticos e a diminuição ou ausência de sedimentos siliciclásticos. Como principal diferença entre os microciclos tipos II e III, destaca-se a ocorrência de esferulito sindeposicional nos microbialitos formados durante o microciclo III, o que indica condições de estresse ambiental maior do que no microciclo II. As feições de exposição marcadas por dissolução ou erosão nesses dois microciclos são menos fre- quentes, possivelmente em decorrência de que, nos períodos mais áridos, haveria uma menor intensidade de chuvas, reduzindo a dissolução por água meteórica e erosão. Essas feições, no entanto, são comuns nos microbialitos que apresentam o padrão de microciclo tipo I e que se formaram em condições mais úmidas.

Além dos microciclos associados a contextos regressivos, também foi caracterizado o microciclo transgressivo, que caracteriza o desenvolvimento do microbialito durante a fase inicial de expansão do corpo lacustre. Nessa fase, os microbialitos for- 
mam um registro pouco expressivo, em virtude das mudanças ambientais, que se tornam desfavoráveis às condições de batimetria, luminosidade (pelo aporte de sedimentos finos) e da diluição de sais devido a um aumento da precipitação em relação à evaporação.

Agradecimentos - Agradecemos à Petrobras S.A., no âmbito do Programa de Capacitação em Estratigrafia de Alta Resolução (PCEAR), pelo apoio na realização das atividades de campo. Ao laboratório Lagesed da UFRJ, por disponibilizar os recursos de microfotografia para o imageamento das seções petrográficas.

\section{Referências}

Arp, G., Thiel, V., Reimer, A., Michaelis, W. \& Reitner, J. 1999. Biofilm exopolymers control microbialite formation at thermal springs discharging into the alkaline pyramid Lake, Nevada, USA. Sedimentary Geology, 126: 159-176.

Bento Freire, E. 2012. Caracterização estratigráfica em alta resolução das Sequências calcárias de origem microbiana do intervalo paleocênico da Formação Yacoraite (Sequência Balbuena IV) na região de Salta - Argentina. Rio de Janeiro, 223 p. Dissertação de Mestrado, Programa de Pós Graduação em Geologia, Instituto de Geociências, Universidade Federal do Rio de Janeiro.

Bianucci, H. \& Homovc, J.F. 1982. Tectonogénesis de un sector de la Cuenca del Subgrupo Pirgua, noroeste argentino. In: CONGRESO LATINOAMERICANO DE GEOLOGIA, 5, 1982. Buenos Aires. Anais. Buenos Aires: Servicio Geológico Nacional, v1, p.539-546.

Boll, A. 1991. Identificación y correlación de secuencias somerizantes del Miembro Las Avispas (Formación Yacoraite). Noroeste Argentino. In: CONGRESO GEOLÓGICO ARGENTINO, 10‥, 1987, San Miguel de Tucumán/Província de Tucumán . Anais II... Buenos Aires: Asociación Geológica Argentina. 1991. v.1, p.153-156.

Braga, J.C., Martín, J.M. \& Riding, R. 1995. Controls on microbial dome fabric development along a carbonate-siliciclastic shelfbasin transect, Miocene, SE Spain. Palaios, 10: 347-361.

Bunevich, R.B. 2016. Caracterização e interpretação bioarquitetural de microbialitos lacustres da sequência Balbuena IV (Daniano) bacia de Salta - Argentina. Rio de Janeiro, 170 p. Dissertação de Mestrado, Programa de Pós Graduação em Geologia, Instituto de Geociências, Universidade Federal do Rio de Janeiro.

Burne, R.V. \& Moore, L. 1987. Microbialites; organosedimentary deposits of benthic microbial communities. Palaios, 2: 241-254.

Cameron, B., Cameron, D. \& Jones, J.R. 1985. Modern algal mats in intertidal and supratidal quartz sands, northeastern Massachusetts, USA. In: Curren H. A. (Ed.). Biogenic Structures: Their Use in Interpreting Depositional Environments. Tulsa, OK: Society of
Economic Paleontologists and Mineralogists. SEPM special publication, 35, p. 211-235.

Chafetz, H. S. \& Buczynski, C. 1992. Bacterially induced lithification of microbial mats. Palaios, 7: 277-293.

Corbett, P., Hayashi, F. Y., Alves, M. S., Jiang, Z., Wang, H., Demyanov, V., Machado, A., Borghi, L. \& Srivastava, N. 2015. Microbial carbonates: a sampling and measurement challenge for petrophysics addressed by capturing the bioarchitectural components. In: Bosence, D. W. J., Gibbons, K. A., Le Heron, D. P., Morgan, W. A. Pritchard, T. \& Vining, B. A. (Ed.). Microbial Carbonates in Space and Time: Implications for Global Exploration and Production. Geological Society, London, Special Publications. p. 69-85.

Danielli, H.M.C. \& Edington, M.A. 1983. Bacterial calcification in limestone caves. Geomicrobiology Journal, 3: 1-16.

Deelman, J.C. 1975. Two mechanisms of microbial carbonate precipitation. Naturwissenschaften, 62: 484485.

Deelman, J.C. 1978. Experimental ooids and grapestones: Carbonate aggregates and their origin. Journal of Sedimentary Petrology, 48: 503-512.

Del Moral. A., Roldan, E., Navarro, A., Monteoliva, M., \& Ramos Cormenzana, A. 1987. Formation of calcium carbonate crystals by moderately halophilic bacteria. Geomicrobiology Journal, 5: 79-87.

Del Papa, C.E. \& Salfity, J.A. 1999. Non-marine Paleogene sequences, Salta Group, Northwest Argentina. Acta Geologica Hispanica, 34(2-3): 105-122.

Dittrich, M. \& Sibler, S. 2010. Calcium carbonate precipitation by cyanobacterial polysaccarides. In: Pedley, H.M. \& Rogerson, M. (Ed.). Speleothems and Tufas: Unravelling Physical and Biological Controls. Geological Society of London, p. 51-63.

Gerdes, G., Krumbein, W.E. \& Noffke, N. 2000. Evaporite microbial sediments. In: R. Riding, R., \& Awramik, S. M. (Ed.). Microbial Sediments. Berlin: Springer, p. 196-208.

Girardclos, S. 1993, Enregistrement des Evénements de Haute Energie et Formation d'Ooïdes dans des Sédiments Littoraux du Léman (Petit-Lac). Genève, 112 p. Diploma thesis, Dept. Sciences de la Terre, Université de Genève.

Gomes, J.P.B. 2013. Simulação de processos deposicionais: caracterização de dois ciclos de alta frequência da Sequência Balbuena IV, Bacia do Noroeste Argentino. Porto Alegre, 225 p. Dissertação de Mestrado, Programa de Pós Graduação em Geociências, Instituto de Geociências, Universidade Federal do Rio Grande do Sul.

Hernández, R., Disalvo, A., Boll, A. \& Gómez Omil, R. 1999. Estratigrafía secuencial del Grupo Salta, com enfasis em las subcuencas de Metan-Alemania, noroeste Argentino. In: CONGRESO GEOLÓGICO ARGENTINO, 14, 1999. Salta. Relatorio: Geologia del Noroeste Argentino. Salta: Universidade Nacional de Salta, p. 264-284.

Lippman, F. 1973. Sedimentary Carbonate Minerals. Berlin, Springer-Verlag, 228p.

Logan, B.W., Hoffman, P. \& Gebelein, C.D. 1974. Algal 
mats, cryptalgal fabrics, and structures, Hamelin Pool, Western Australia. American Association of Petroleum Geologists, Memoir, 22: 140-194.

Marquillas, R.A., Del Papa, C. \& Sabino, I.F. 2005. Sedimentary aspects and paleoenvironmental evolution of a rift basin: Salta Group (Cretaceous-Paleogene), northwestern Argentina. International Journal of Earth Sciences, 54(1): 94- 113.

Marquillas, R. A., Sabino, I. F., Nóbrega, Sial, A., Del Papa, C., Ferreira, V., \& Matthews, S. 2007. Carbon and oxygen isotopes of Maastrichtian-Danian shallow marine carbonates: Yacoraite Formation, northwestern Argentina. Journal of South American Earth Sciences. 23(4): 304-320.

Mercedes-Martín, R.,Rogerson, M.R., Brasier, A.T., Vonhof, H.B., Prior, T.J., Fellows, S.M., Reijmer, J.J.G., Billing, I., Pedley, H.M. 2016. Growing spherulitic calcite grains in saline, hyperalkaline lakes: experimental evaluation of the effects of Mg-clays and organic acids. Sedimentary Geology, 335: 93-102.

Pedley, H.M. 1994. Prokaryote-microphyte biofilms and tufas: a sedimentological perspective. Kaupia, 4: 4560.

Pedrinha Guimarães, S. 2014. Análise estratigráfica em depósitos lacustres Maastrichtianos da formação Yacoraite (bacia de): definição e rastreabilidade de sequências de alta resolução. Rio Claro, 148 p. Programa de Pós Graduação em Geociências e Meio Ambiente, Instituto de Geociências e Ciências Exatas, Dissertação de Mestrado, Universidade Estadual Júlio de Mesquita.

Pentecost, A. 1990. The formation of travertine shrubs: Mammoth hot Springs, Wyoming. Geological Magazine, 127: 159-168.

Riding, R. 2011. Microbialites, stromatolites, and thrombolites. In: Reitner, J., \& Thiel, V., (Ed.). Encyclopedia of Geobiology, Encyclopedia of Earth Sciences Series: Springer Netherlands, p. 635-654.

Roemers de Oliveira, E. 2014. Contexto deposicional da Sequência Balbuena III (Maastrichtiano/Daniano) da formação Yacoraite na Sub-bacia Metán-Alemania, na região de Salta, Argentina. Rio Claro, 181p. Programa de Pós Graduação em Geociências e Meio Ambiente, Instituto de Geociências e Ciências Exatas, Dissertação de Mestrado, Universidade Estadual Júlio de Mesquita.

Manuscrito 597

Editores: Ana Maria P. Mizusaki \& Paulo A. Souza.
Sabino, I.F. 2004. Estratigrafía de la Formación La Yesera (Cretácico): Base del relleno sinrift del Grupo Salta, noroeste argentino. Revista de la Asociación Geologica Argentina, 59(2): 330-340.

Salfity, J.A. \& Marquillas, R.A. 1989. El basamento pré-cretácico de la Argentina septentrional y regiones adyacentes. Comunicaciones. 40:17-28.

Salfity, J.A. \& Marquillas, R.A. 1994. Tectonics and sedimentary evolution of the Cretaceous-Eocene Salta Group Basin, Argentina. In: Salfity, J.A. (Ed.). Cretaceous Tectonics of the Andes: Wiesbaden, Germany, Friedrich Vieweg \& Sohn, Earth Evolution Sciences, p. 266-315.

Sami, T.T. \& James, N.P. 1996. Synsedimentary cements as Paleoproterozoic platform building blocks, Pethei Group, northwestern Canada. Journal of Sedimentary Research. 66: 209-222.

Schwarzacher, W. 1993. Cyclostratigraphy and the Milankovich Teory. Developments in Sedimentology. Amsterdam, Elsevier, 225p.

Shapiro, R. S. \& Awramik, S. M. 2006. Favosamaceria cooperi new group and form: a widely dispersed, time-restricted thrombolite. Journal of Paleontology, 80: 411-422.

Terra, G.J.S. Rodrigues, E.B. Bento Freire, E. Lykawka, R. Raja Gabaglia, G.P. Hernández, R.M. \& Hernández, J.I. 2012. Salta Basin, Argentina: A Good Analog for Phanerozoic Lacustrine Microbialite-Bearing Reservoirs. In: AMERICAN ASSOCIATION OF PETROLEUM GEOLOGISTS, HEDBERG CONFERENCE: MICROBIAL CARBONATE RESERVOIR CHARACTERIZATION, Houston Texas, Abstracts, Jun 2012. Disponível em: http://www.searchanddiscovery.com/pdfz/abstracts/pdf/2012/90153hedberg/abstracts/ndx_tonietto.pdf.html acesso em março 2017.

Verrecchia, E.P., Freytet, P., Verrecchia, K.E. \& Dumont, J.L. 1995. Spherulites in calcrete laminar crusts; biogenic $\mathrm{CaCO}_{3}$ precipitation as a major contributor to crust formation. Journal of Sedimentary Research. 65: 690-700.

Vogt, T. 1987. Quelques microstructures de croûtes calcaires quarternaires d'Afrique du Nord, In: Fédoroff, N., Bresson, L.M. \& Courty, M.A. (Ed.). Micromorphologie des Sols. Association Française pour l' Etude du Sol. p. 563-568. 
